\title{
Structural and electronic features of triphenylstibine- functionalized Fischer carbene complexes of Molybdenum(0)
}

Armand Jansen van Rensburg, ${ }^{a}$ Marilé Landman, ${ }^{a *}$ Petrus H. van Rooyen, ${ }^{a}$ Marrigje M. Conradie, ${ }^{b}$ Elizabeth Erasmus, ${ }^{b}$ Jeanet Conradie ${ }^{b *}$

a Department of Chemistry, University of Pretoria, Private Bag X20, Hatfield, 0028, South Africa. Tel: +27-12-4202527, Fax: +27-12-4204687

b Department of Chemistry, University of the Free State, PO Box 339, Bloemfontein, 9300, South Africa. Tel: +27-51-4012194, Fax: +27-51-4017295

Contact author details:

Name: Jeanet Conradie, Tel: ++27-51-4012194, Fax: ++27-51-4017295, email: conradj@ufs.ac.za

Name: Marilé Landman, Tel: ++27-12-4202527, Fax: ++27-12-4204687, email: marile.landman@up.ac.za

\section{Keywords}

Fischer carbene; molybdenum; triphenylstibine; DFT; XPS

\section{Graphical abstract}

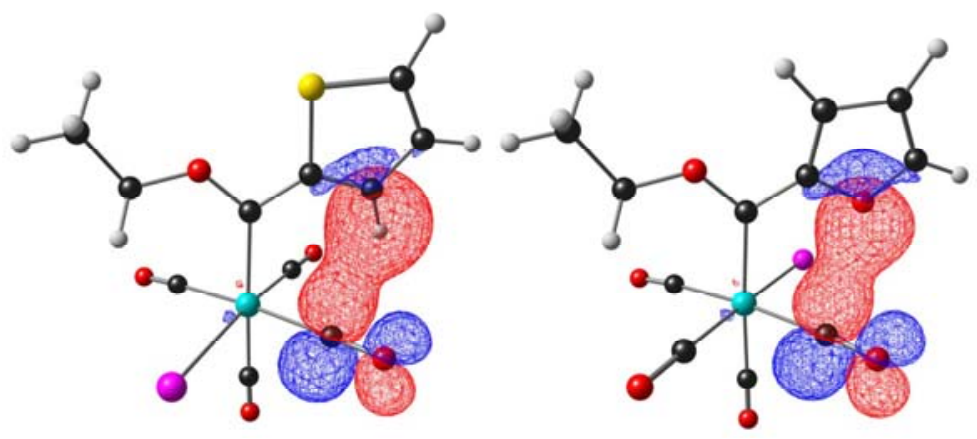




\title{
Synopsis
}

X-ray crystal structures, DFT, NBO and QTAIM calculations and XPS measurements of novel triphenylstibine-functionalized molybdenum(0) Fischer carbene complexes.

\section{Highlights}

- $\quad$ X-ray structure of novel triphenylstibine containing $\mathrm{Mo}(0)$ Fischer carbene complexes

- $\quad \mathrm{X}$-ray photoelectron spectroscopy binding energies of Mo $3 \mathrm{~d}_{5 / 2}$ photoelectron lines

- $\quad \mathrm{X}$-ray photoelectron spectroscopy binding energies of $\mathrm{Sb} 2 \mathrm{p}_{3 / 2}$ photoelectron lines

- $\quad$ QTAIM bonding paths stabilize preferred orientation of aryl carbene substituent

- Interactions between donor and empty acceptor NBOs stabilize aryl group orientation

\begin{abstract}
The synthesis and characterization of the first triphenylstibine-containing Fischer carbene complexes of $\mathrm{Mo}(0)$ with general formula $\left[\left(\mathrm{SbPh}_{3}\right)(\mathrm{CO}) 4 \mathrm{MoC}(\mathrm{OEt})(\mathrm{Ar})\right]$ with $\mathrm{Ar}=2$-thienyl (1), 2 furyl (2), 2-(N-methyl)pyrrolyl (3), and 2,2'-bithienyl (4) are reported. The solid state crystal structures of these complexes show a syn conformation of the 2-thienyl and 2,2'-bithienyl groups relative to the ethoxy group, and an anti conformation of the 2-furyl group relative to the ethoxy group. Density functional theory calculations using natural bonding orbital (NBO) and quantum theory of atoms in molecules (QTAIM) calculations gave insight into the electronic structure and preferred conformations of these novel complexes. X-ray photoelectron spectroscopy measurements show that the binding energy of the Mo $3 \mathrm{~d}_{5 / 2}$ photoelectron line for the 2-(N-methyl)pyrrolylcontaining Fischer carbene complex, 3, is the smallest; followed by $\mathbf{2}$ and then $\mathbf{1}$. This implies that the Mo metal centre is more electron rich in 3, relative to the 2-furyl or 2-thienyl containing Fischer carbene complexes, 2 and $\mathbf{1}$, respectively.
\end{abstract}

\section{Introduction}

The unique reactivity patterns of Fischer carbene complexes simplified the production of specialized and previously-inaccessible compounds [1]. Fischer carbene complexes have been employed in the production of fused polyaromatic compounds, such as antibiotics [2] and vitamins [3], as well as in the synthesis of cyclopropane derivatives [4]. Fischer carbene complexes are often prone to decomposition [5]. Enhancement of the stability of these complexes is thus required, 
without detrimental loss of reactivity. Previous reports showed that the incorporation of tertiary pnictogen derivatives $\left(\mathrm{ER}_{3}, \mathrm{E}=\mathrm{P}, \mathrm{As}, \mathrm{Sb}\right.$, and $\mathrm{R}=$ alkyl, aryl $)$ into the coordination sphere of a Fischer carbene complex produced complexes of type cis/trans $-\left[\left(\mathrm{ER}_{3}\right)(\mathrm{CO}){ }_{4} \mathrm{MC}(\mathrm{OR})\left(\mathrm{R}^{\prime}\right)\right](\mathrm{R}=\mathrm{Me}$, Et, R' = Me, Ph, M = Cr, W), which exhibited superior air-stability over their pentacarbonyl analogues [6-8]. Pnictogen-substituted Fischer carbene complexes are thus promising candidates for use in academic and industrial applications.

Our research group expanded the field of heteroarene-based Fischer carbene complexes of $\operatorname{Mo}(0)$ through the incorporation of ligands such as triphenylphosphine [9-12], 1,2bis(diphenylphopshino)ethane [10,11] and triphenylarsine [12] into the coordination sphere. Valuable insights into the structural and electronic aspects of the pnictogen-substituted Fischer carbene complexes were obtained. Fischer and Aumann [6] prepared cis$\left[\left(\mathrm{SbPh}_{3}\right)(\mathrm{CO})_{4} \mathrm{WC}(\mathrm{OMe})(\mathrm{Ph})\right]$, and Fischer and Richter [8] prepared cis$\left[\left(\mathrm{SbR}_{3}\right)(\mathrm{CO})_{4} \mathrm{CrC}(\mathrm{OMe})(\mathrm{Me})\right](\mathrm{R}=\mathrm{Me}, \mathrm{Et}, \mathrm{Cy})$ and trans $-\left[\left(\mathrm{SbR}_{3}\right)(\mathrm{CO})_{4} \mathrm{CrC}(\mathrm{OMe})(\mathrm{Me})\right](\mathrm{R}=\mathrm{Me}$, $\mathrm{Ph}, \mathrm{Cy})$. To date, no stibine-containing Fischer carbene complex of $\mathrm{Mo}(0)$ is known. To complement previous studies of our group [9-12], and to supplement the number of stibinesubstituted Fischer carbene complexes in literature, the synthesis, structural investigation, X-ray photoelectron spectroscopic (XPS) study and theoretical examination of four novel $\mathrm{SbPh}_{3}-$ subsituted Fischer carbene complexes of $\mathrm{Mo}(0)$ (Figure 1) are reported here.

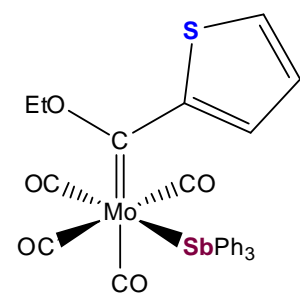

1

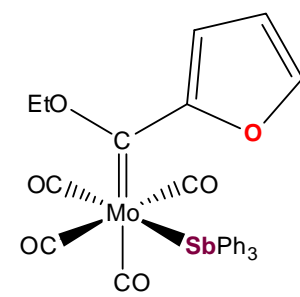

2

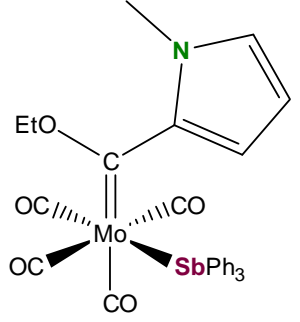

3

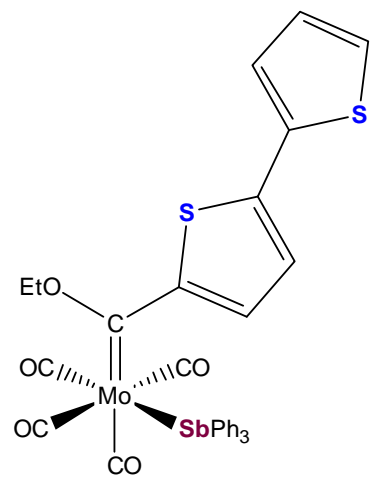

4

Figure 1. $\mathrm{SbPh}_{3}$-substituted Fischer ethoxycarbene complexes of molybdenum(0) 


\section{Experimental}

\subsection{Synthesis}

Tetrahydrofuran (THF), hexane, and dichloromethane (DCM) were dried and distilled under argon or nitrogen atmospheres prior to use. Column chromatography was carried out under a nitrogen atmosphere at $-40{ }^{\circ} \mathrm{C}$, with silica gel (particle size $0.063-0.200 \mathrm{~mm}$ ) as stationary phase. Percentage yields were calculated relative to the limiting reagent. Crystals were grown using vapour diffusion methods with hexane and DCM as crystallization solvents. Triethyloxonium tetrafluoroborate was prepared according to a literature method [13]. Thiophene [14], Nmethylpyrrole [15], and N,N,N',N'-tetramethylethylenediamine (TMEDA) [15] were purified according to literature methods. Molybdenum(0) hexacarbonyl, furan, 2,2'-bithiophene, triphenylstibine, and n-butyllithium $\left(1.6 \mathrm{~mol} \cdot \mathrm{dm}^{-3}\right.$ in hexane) were used as purchased. ${ }^{1} \mathrm{H}$ and ${ }^{13} \mathrm{C}$ nuclear magnetic resonance (NMR) spectra were recorded on a Bruker ARX-300 spectrometer in $\mathrm{CDCl}_{3}$, using the solvent residual peak as the internal reference, at 300.1 and $75.5 \mathrm{MHz}$, respectively. Infrared (IR) spectra were recorded on a Perkin Elmer Spectrum RXI FT-IR spectrophotometer as potassium bromide pellets, and only the vibration bands in the carbonylstretching region $\left(1500-2200 \mathrm{~cm}^{-1}\right)$ are reported. Mass spectra were recorded on a SYNAPT G2 HDMS instrument, using electrospray ionisation as the ion source and a time-of-flight mass analyser. A sampling time of 3 minutes was used, with the direct infusion inlet method. The pentacarbonyl Fischer carbene complexes, [(CO) $\left.{ }_{5} \mathrm{MoC}(\mathrm{OEt})\left(\mathrm{C}_{4} \mathrm{H}_{3} \mathrm{~S}\right)\right] \quad$ (1a) [16], $\left[(\mathrm{CO})_{5} \mathrm{MoC}(\mathrm{OEt})\left(\mathrm{C}_{4} \mathrm{H}_{3} \mathrm{O}\right)\right] \quad$ (2a) $\quad[9], \quad\left[(\mathrm{CO})_{5} \mathrm{MoC}(\mathrm{OEt})\left(\mathrm{C}_{4} \mathrm{H}_{3} \mathrm{NMe}\right)\right] \quad$ (3a) $\quad[12]$ $\left[(\mathrm{CO})_{5} \mathrm{MoC}(\mathrm{OEt})\left(\mathrm{C}_{8} \mathrm{H}_{5} \mathrm{~S}_{2}\right)\right]$ (4a) [12], were prepared and purified according to literature. Refer to Figure 3 - Figure 5 for the atom numbering schemes of $\mathbf{1}$, 2, and $\mathbf{4}$, respectively.

\subsubsection{Synthesis of $c i s-\left[\left(\mathrm{SbPh}_{3}\right)(\mathrm{CO})_{4} \mathrm{MoC}(\mathrm{OEt})\left(\mathrm{C}_{4} \mathrm{H}_{3} \mathrm{~S}\right)\right](\mathbf{1})$}

A stirred solution of $1 \mathrm{a}(0.19 \mathrm{~g}, 0.5 \mathrm{mmol})$ and $\mathrm{SbPh}_{3}(0.19 \mathrm{~g}, 0.55 \mathrm{mmol})$ in hexane $(40 \mathrm{~m} \ell)$ was heated to refluxing temperature. After two hours, the solution colour changed from red to brownred. Thin-layer chromatography (TLC) analysis (hexane-DCM (4:1)) revealed the formation of a dark brown product. Heating was ceased and the solvent was removed under reduced pressure. The resulting brown-red residue was purified on a $20 \mathrm{~cm}$ silica gel column at $-40{ }^{\circ} \mathrm{C}$. A red fraction was eluted with hexane, which corresponded to 1a. A dark brown fraction was eluted using hexaneDCM gradient elution, which corresponded to $\mathbf{1}$. After solvent removal, $\mathbf{1}$ was isolated as a dark brown powder $(0.21 \mathrm{~g}, 0.30 \mathrm{mmol}, 60 \%)$. 
${ }^{1} \mathrm{H}$ NMR $\left(\mathrm{CDCl}_{3}, \mathrm{ppm}\right) \delta 8.09\left(\mathrm{~d}, 1 \mathrm{H}, \mathrm{J}_{\mathrm{H}-\mathrm{H}}=4.0 \mathrm{~Hz}, \mathrm{H} 8\right), 7.57\left(\mathrm{~d}, 1 \mathrm{H}, \mathrm{J}_{\mathrm{H}-\mathrm{H}}=4.7, \mathrm{H} 10\right), 7.32-7.50$ $\left(\mathrm{m}, 15 \mathrm{H}, \mathrm{Sb} \underline{\mathrm{Ph}_{3}}\right), 6.95$ (t, 1H, J $\left.\mathrm{J}_{-\mathrm{H}}=4.7 \mathrm{~Hz}, \mathrm{H} 9\right), 4.89$ (q, 2H, J $\left.\mathrm{J}_{-\mathrm{H}}=7.1 \mathrm{~Hz}, \mathrm{H} 11\right), 1.33\left(\mathrm{t}, 3 \mathrm{H}, \mathrm{J}_{\mathrm{H}-\mathrm{H}}\right.$ $=7.1 \mathrm{~Hz}, \mathrm{H} 12) ;{ }^{13} \mathrm{C}\left\{{ }^{1} \mathrm{H}\right\} \mathrm{NMR}\left(\mathrm{CDCl}_{3}, \mathrm{ppm}\right) \delta 312.5$ (C6), 215.9 (C1), 210.5 (C3), 206.1 (C2 and C4), 157.1 (C7), 140.2 (C10), 135.2 (C21), 133.6 (C20) 133.4 (C8), 130.0 (C23), 129.2 (C22), 128.3 (C9),77.2 (C11), 14.8 (C12); IR (KBr, v(CO)/cm $\left.{ }^{-1}\right)$ 2012, m (A $\left.\mathrm{A}_{1}^{1}\right), 1920$, s (A $\left.\mathrm{A}_{1}^{2}\right), 1909$, s (B1), 1891, s (B $)$; MS (m/z): Calc. $701.94[\mathrm{M}]^{+}$, Exp. $702.9[\mathrm{M}+\mathrm{H}]^{+}$.

\subsubsection{Synthesis of $c i s-\left[\left(\mathrm{SbPh}_{3}\right)(\mathrm{CO})_{4} \mathrm{MoC}(\mathrm{OEt})\left(\mathrm{C}_{4} \mathrm{H}_{3} \mathrm{O}\right)\right](2)$}

A solution of $2 \mathrm{a}(0.18 \mathrm{~g}, 0.5 \mathrm{mmol})$ and $\mathrm{SbPh}_{3}(0.19 \mathrm{~g}, 0.55 \mathrm{mmol})$ in hexane $(40 \mathrm{~m} \ell)$ was stirred at reflux temperature for 2 hours. The solution colour changed from red to brown, and TLC analysis (hexane-DCM (4:1)) indicated the formation of a brown compound. Heating was stopped and the solvent was removed in vacuo. The resulting brown residue was purified using a $20 \mathrm{~cm}$ silica gel column at $-40{ }^{\circ} \mathrm{C}$, using hexane-DCM gradient elution. A red fraction, corresponding to unreacted 2a, was eluted, followed by a red-brown fraction, corresponding to $\mathbf{2}$. After solvent removal, 2 was obtained as a brown crystalline powder $(0.2 \mathrm{~g}, 0.29 \mathrm{mmol}, 58 \%)$.

${ }^{1} \mathrm{H}$ NMR $\left(\mathrm{CDCl}_{3}, \mathrm{ppm}\right) \delta 7.36-7.43\left(\mathrm{~m}, 15 \mathrm{H}, \mathrm{Sb}_{\underline{P h}}\right) 7.12\left(\mathrm{~d}, 1 \mathrm{H}, \mathrm{J}_{\mathrm{H}-\mathrm{H}}=1.6 \mathrm{~Hz}, \mathrm{H} 10\right), 6.71(\mathrm{~d}, 1 \mathrm{H}$, $\left.\mathrm{J}_{\mathrm{H}-\mathrm{H}}=3.6 \mathrm{~Hz}, \mathrm{H} 8\right), 6.28\left(\mathrm{dd}, 1 \mathrm{H}, \mathrm{J}_{\mathrm{H}-\mathrm{H}}=1.7 \mathrm{~Hz}, 3.6 \mathrm{~Hz}, \mathrm{H} 9\right), 4.39$ (q, 2H, $\left.\mathrm{J}_{\mathrm{H}-\mathrm{H}}=7.0 \mathrm{~Hz}, \mathrm{H} 11\right), 1.40$ $\left(\mathrm{t}, 3 \mathrm{H}, \mathrm{J}_{\mathrm{H}-\mathrm{H}}=7.1 \mathrm{~Hz}, \mathrm{H} 12\right)$; IR (KBr, $\left.v(\mathrm{CO}) / \mathrm{cm}^{-1}\right)$ 2017, m $\left(\mathrm{A}_{1}^{1}\right), 1937, \mathrm{~s}\left(\mathrm{~A}_{1}^{2}\right), 1899$, s $\left(\mathrm{B}_{1}\right), 1874, \mathrm{~s}$ $\left(\mathrm{B}_{2}\right), \mathrm{MS}(\mathrm{m} / \mathrm{z})$ : Calc. $685.96[\mathrm{M}]^{+}$, Exp. $687.0[\mathrm{M}+\mathrm{H}]^{+}$. The instability of 2 in solution prevented ${ }^{13} \mathrm{C}$ NMR analyses.

\subsubsection{Synthesis of $c i s-\left[\left(\mathrm{SbPh}_{3}\right)(\mathrm{CO})_{4} \mathrm{MoC}(\mathrm{OEt})\left(\mathrm{C}_{4} \mathrm{H}_{3} \mathrm{NMe}\right)\right](3)$}

A solution of 3a $(0.19 \mathrm{~g}, 0.5 \mathrm{mmol})$ and $\mathrm{SbPh}_{3}(0.19 \mathrm{~g}, 0.55 \mathrm{mmol})$ in hexane $(40 \mathrm{~m} \ell)$ was stirred under reflux conditions for 2 hours. During this time, the solution changed colour from orange to red-orange. TLC analysis (hexane-DCM (3:2)) indicated the formation of a red compound. Heating was stopped and the solvent was removed in vacuo. The red residue was purified using a $20 \mathrm{~cm}$ silica gel column at $-40{ }^{\circ} \mathrm{C}$, using hexane-DCM gradient elution. An orange fraction was eluted, which corresponded to unreacted 3a. As elution continued, a red fraction was observed, but converted to an orange fraction before isolation could be achieved. Spectral characterisation of this fraction matched that of 3a. Instead of cold column chromatography, the red residue was washed with cooled hexane $\left(-10^{\circ} \mathrm{C}, 4 \times 20 \mathrm{~m} \ell\right)$. An orange-red residue was obtained, which was employed in subsequent characterization and analysis. 
IR (KBr, v(CO)/cm $\left.{ }^{-1}\right)$ 2010, w $\left(\mathrm{A}_{1}^{1}\right), 1926, \mathrm{~m}\left(\mathrm{~A}_{1}^{2}\right), 1907, \mathrm{~m}\left(\mathrm{~B}_{1}\right), 1865, \mathrm{~m}\left(\mathrm{~B}_{2}\right)$; MS (m/z): Calc. $698.99[\mathrm{M}]^{+}$, Exp. $700.0[\mathrm{M}+\mathrm{H}]^{+}$. The high instability of $\mathbf{3}$ in solution prohibited any NMR analyses of this complex.

\subsubsection{Synthesis of $\left.c i s-\left[\left(\mathrm{SbPh}_{3}\right)(\mathrm{CO})_{4} \mathrm{MoC}(\mathrm{OEt})\left(\mathrm{C}_{8} \mathrm{H}_{5} \mathrm{~S}_{2}\right)\right]\right]$ (4)}

A solution of $4 \mathbf{a}(0.23 \mathrm{~g}, 0.5 \mathrm{mmol})$ and $\mathrm{SbPh}_{3}(0.19 \mathrm{~g}, 0.55 \mathrm{mmol})$ in hexane $(40 \mathrm{~m} \ell)$ was heated to refluxing temperature. The solution was stirred under at this temperature for 2 hours, resulting in a colour change from crimson to purple. TLC analysis (hexane-DCM (4:1)) indicated the formation of a purple compound. Heating was terminated and the solvent was removed under reduced pressure. The resulting purple-red residue was purified using a $20 \mathrm{~cm}$ silica gel column at $-40{ }^{\circ} \mathrm{C}$. A crimson fraction was eluted with hexane, which corresponded to unreacted 4a. A purple fraction, which corresponded to 4, was eluted with hexane-DCM gradient elution. After solvent removal, 4 was obtained as a purple solid $(0.24 \mathrm{~g}, 0.31 \mathrm{mmol}, 61 \%)$.

${ }^{1} \mathrm{H}$ NMR $\left(\mathrm{CDCl}_{3}, \mathrm{ppm}\right) \delta 7.96\left(\mathrm{~d}, 1 \mathrm{H}, \mathrm{J}_{\mathrm{H}-\mathrm{H}}=4.3 \mathrm{~Hz}, \mathrm{H} 8\right), 7.44\left(\mathrm{dd}, 1 \mathrm{H}, \mathrm{J}_{\mathrm{H}-\mathrm{H}}=1.1 \mathrm{~Hz}, 3.6 \mathrm{~Hz}, \mathrm{H} 16\right)$, 7.36 (s(br), 1H, H14), 7.06 (dd, 1H, J $\left.\mathrm{H}_{-\mathrm{H}}=3.6 \mathrm{~Hz}, 5.1 \mathrm{~Hz}, \mathrm{H} 15\right), 6.99$ (d, 1H, J 4.87 (q, 2H, JH-H $=7.1 \mathrm{~Hz}, \mathrm{H} 11), 1.34$ (t, 3H, J 1928, s $\left(\mathrm{A}_{1}^{2}\right), 1904$, vs $\left(\mathrm{B}_{1}\right), 1890$, vs $\left(\mathrm{B}_{2}\right)$; MS (m/z): Calc. $783.92[\mathrm{M}]^{+}$, Exp. $784.8[\mathrm{M}+\mathrm{H}]^{+}$. The instability of $\mathbf{4}$ in solution prevented ${ }^{13} \mathrm{C}$ NMR analyses.

\subsection{Crystal structure analysis}

Crystals suitable for single crystal X-ray diffraction were obtained for $\mathbf{1}, \mathbf{2}$, and $\mathbf{4}$. Crystal data were collected at $150 \mathrm{~K}$ on a Bruker D8 Venture kappa geometry diffractometer with duo I $\mu$ s sources, a Photon 100 CMOS detector and APEX II [17] control software using Quazar multi-layer optics monochromated, Mo-K $\alpha$ radiation by means of a combination of $\phi$ and $\omega$ scans. Data reduction was performed using SAINT+ [17] and the intensities were corrected for absorption using SADABS [17]. The structures were solved by intrinsic phasing using SHELXTS [18] and refined by full-matrix least squares using SHELXTL and SHELXL-2014 [18]. In the structure refinement, all hydrogen atoms attached to carbon atoms were added in calculated positions and treated as riding on the atom to which they are attached. All non-hydrogen atoms were refined with anisotropic displacement parameters, all isotropic displacement parameters for hydrogen atoms were calculated as $\mathrm{X} \times$ Ueq of the atom to which they are attached, $\mathrm{X}=1.5$ for the methyl hydrogens and 1.2 for all other hydrogens. Crystal data, data collection, structure solution and refinement details are available in each CIF. ORTEP drawings [19] of the structures (Figure 1) are 
given in Figure 3 - Figure 5, showing the numbering system used with ADP's at the 50\% probability level.

\subsection{Theoretical calculations}

Density functional theory (DFT) calculations were performed with the hybrid functional B3LYP [20,21] (20\% Hartree-Fock exchange) [22] as implemented in the Gaussian 09 program package [23]. Geometries of the neutral complexes were optimized in gas phase with the triple- $\zeta$ basis set 6 $311 \mathrm{G}(\mathrm{d}, \mathrm{p})$ on all atoms except Mo and Sb, where def2-TZVPP [24] was used. Energies reported are gas phase electronic energies. Natural bonding orbital (NBO) calculations [25-28] were performed on the optimized structures by the NBO 3.1 module [29] in Gaussian 09 at the same level of theory. An electronic density analysis (using Bader's quantum theory of atoms in molecules (QTAIM) [3032], as implemented in ADF 2013 [33-35]), at the same level of theory, were performed on the optimized structures.

\section{$2.4 \quad X$-ray photoelectron spectroscopy}

The X-ray photoelectron spectroscopic (XPS) analysis was carried out with a PHI 5000 Versaprobe using monochromatic Al Ka X-ray radiation $(h v=1253.6 \mathrm{eV})$. The hemispherical analyser pass energy used to record the high resolution spectra were maintained at $29.35 \mathrm{eV}$ for $\mathrm{C} 1 \mathrm{~s}$ and $\mathrm{O} 1 \mathrm{~s}$, and $93.90 \mathrm{eV}$ for Mo 3d, S 2p, Sb 2p and N 1s in order to obtain peaks with good resolution, using a $1 \mathrm{eV} / \mathrm{step}$. To acquire a neutral charge on the surface of the sample, a low energy electron beam was utilized. All the binding energies of the photoelectron spectra were referenced against the lowest binding energy of the adventitious $\mathrm{C} 1 \mathrm{~s}$ photoelectron line, which was set to be at $284.8 \mathrm{eV}$. The XPS data was interpreted using Multipak version 9.7 computer software [36].

\section{Results and discussion}

\subsection{Synthesis}

The production of mono-substituted tetracarbonyl Fischer carbene complexes are most often achieved through two general methods [6-8]. The first method entails converting a metal hexacarbonyl complex to the corresponding pentacarbonyl Fischer carbene complex [8,37], followed by ligand substitution to produce both cis- and trans-substituted tetracarbonyl Fischer carbene complexes [8]. The second method involves carbonyl substitution of a metal hexacarbonyl 
complex, and the resulting substituted pentacarbonyl complex is then subjected to carbene synthesis to yield the cis-substituted tetracarbonyl Fischer carbene complex [6]. Both of these methods have been successfully employed in the synthesis of phosphine- and arsine-substituted Fischer carbene complexes [6-11,38]. However, Fischer and Aumann [6] observed that the second method outlined here does not generate the desired substituted Fischer carbene complex, cis$\left[\left(\mathrm{SbPh}_{3}\right)(\mathrm{CO})_{4} \mathrm{WC}(\mathrm{OMe})(\mathrm{Me})\right]$, as the antimony-atom is open to nucleophilic attack. Therefore, the first method was selected for the synthesis of $\mathbf{1}-\mathbf{4}$, and is outlined in Scheme 1. Carbonyl substitution was conducted thermally [39], since ultraviolet irritation of Fischer carbene complexes is known to generate additional side-products [40] along with the substitution product [41].
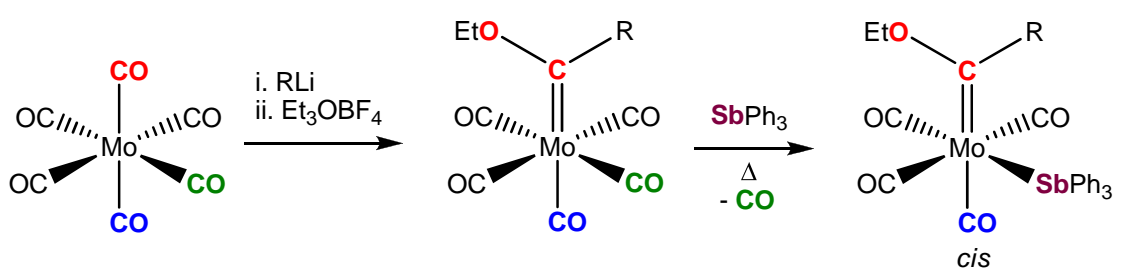

Scheme 1. Synthetic route to $c i s$-substituted tetracarbonyl Fischer carbene complexes containing $\mathrm{SbPh}_{3}$, with $\mathrm{R}=2$ thienyl (1), 2-furyl (2), 2-(N-methyl)pyrrolyl (3), 2,2'-bithienyl (4)

In this study the classic Fischer method [37] was used in the production of the pentacarbonyl Fischer carbene complexes 1a - 4a $[9,12,16]$. These complexes served as starting materials in carbonyl substitution reactions. The method employed in the synthesis of the triphenylphosphine and triphenylarsine analogues, cis- $\left[\left(\mathrm{EPh}_{3}\right)(\mathrm{CO})_{4} \mathrm{MoC}(\mathrm{OEt})(\mathrm{R})\right](\mathrm{E}=\mathrm{P}, \mathrm{As})[12]$, as shown in Scheme 1, was used to convert $\mathbf{1 a}-\mathbf{4 a}$ into $\mathbf{1}-\mathbf{4}$, respectively. TLC revealed the production of only one substitution product. Column chromatography at $-40{ }^{\circ} \mathrm{C}$ was utilized for the purification of 1 4, using hexane and dichloromethane gradient elution. This was successful for 1, 2 and 4, as these complexes could be isolated. A red compound was observed during the synthesis of cis$\left[\left(\mathrm{SbPh}_{3}\right)(\mathrm{CO})_{4} \mathrm{MoC}(\mathrm{OEt})\left(\mathrm{C}_{4} \mathrm{H}_{3} \mathrm{NMe}\right)\right]$ via TLC analysis. A red fraction was also observed during the cold column chromatography, but decomposed to an orange-yellow compound as elution continued. The crude product of 3 , which is composed of $3(\sim 40 \%)$, 3a $(\sim 40 \%)$, and $\mathrm{SbPh}_{3}(\sim 10 \%)$ based on TLC, was used for IR spectroscopy and mass spectrometry. The dissolution of the crude product of 3 resulted in a rapid colour change from red-orange to yellow-orange. Thus, crystallization and NMR analyses of 3 could not be performed. Although substituted tetracarbonyl Fischer carbene complexes have been reported to be more stable than their pentacarbonyl precursors [6], this was not observed in solution for the complexes of this study. Fischer carbene 
complexes of the type $\operatorname{cis}$ - $\left[\mathrm{L}(\mathrm{CO})_{4} \mathrm{MoC}(\mathrm{OEt})\left(\mathrm{C}_{4} \mathrm{H}_{3} \mathrm{NMe}\right)\right]$ decomposed more rapidly in solution for $\mathrm{L}=\mathrm{SbPh}_{3}$ and $\mathrm{L}=\mathrm{AsPh}_{3}$ than for $\mathrm{L}=\mathrm{PPh}_{3}$ or $\mathrm{L}=\mathrm{CO}[12]$.

\subsection{Characterization}

The novel complexes $\mathbf{1}$ - 4 were characterized using ${ }^{1} \mathrm{H}$ and ${ }^{13} \mathrm{C}$ NMR spectroscopy, IR spectroscopy, and electrospray-ionization mass spectrometry. The ${ }^{1} \mathrm{H}$ NMR spectra of $\mathbf{1}, \mathbf{2}$, and 4 showed well-resolved proton signals for the carbene ligand protons. Satisfactory resolution was obtained for the signals of the proton atoms present on the 2,2 '-bithienyl moiety of $\mathbf{4}$, as only the chemical shift of H14 was observed as a broad singlet, instead of an expected doublet of doublets $[12,42,43]$. The phenyl-ring protons of the triphenylstibine ligand were observed as a multiplet with an integration value of 15 for $\mathbf{1}, \mathbf{2}$, and $\mathbf{4}$, which was also reported for the triphenylphosphine [9-12] and triphenylarsine [12] analogues. The high instability of 3 prohibited any NMR analyses of this complex. The NMR spectrum of the yellow-orange decomposition product of $\mathbf{3}$ matched the combined spectra of 3a and free $\mathrm{SbPh}_{3}$.

The instability of 2 and 4 complicated ${ }^{13} \mathrm{C}$ NMR analyses. The ${ }^{13} \mathrm{C}$ NMR spectra obtained for these two complexes matched that of their parent pentacarbonyl complexes, along with free $\mathrm{SbPh}_{3}$. It was concluded that the substituted complexes $\mathbf{2}$ and $\mathbf{4}$ reverted back to $\mathbf{2 a}$ and $\mathbf{4 a}$ due to the presence of carbon monoxide gas in solution, which originated from the decomposition of $\mathbf{2}$ and $\mathbf{4}$. For $\mathbf{3}$, the decomposition and reversion to 3a is so rapid that even ${ }^{1} \mathrm{H}$ NMR analysis was impossible. The 2thienyl complex, 1, exhibited sufficient stability in solution, and a ${ }^{13} \mathrm{C}$ NMR spectrum could be obtained. The carbene carbon (C6) signal of 1 was observed at 312.5 ppm, while the carbonyl carbons were observed at 215.9 ppm (C1), 210.5 ppm (C3), and 206.1 ppm (C2 and C4) with a peak height ratio of 1:1:2. This is indicative of a cis-tetracarbonyl system [44]. In the series of complexes for $c i s-\left[(\mathrm{L})(\mathrm{CO})_{4} \mathrm{MoC}(\mathrm{OEt})\left(\mathrm{C}_{4} \mathrm{H}_{3} \mathrm{~S}\right)\right]$, the carbene carbon was observed at $307.2 \mathrm{ppm}(\mathrm{L}=\mathrm{CO})$ [16], $310.5 \mathrm{ppm}\left(\mathrm{L}=\mathrm{PPh}_{3}\right)$ [12], $311.1 \mathrm{ppm}\left(\mathrm{L}=\mathrm{AsPh}_{3}\right)$ [12], and $312.5 \mathrm{ppm}\left(\mathrm{L}=\mathrm{SbPh}_{3}\right)$ in $\mathrm{CDCl}_{3}$. This successive downfield shift of the carbene carbon signal, although slight, is consistent with the increased metal-to-ligand $\pi$-back donation that occurs when a weaker $\pi$-acceptor ligand is introduced into the coordination sphere [45], and with the decrease of $\pi$-acceptor strength in going from $\mathrm{CO}$ to $\mathrm{PPh}_{3}$ to $\mathrm{AsPh}_{3}$ to $\mathrm{SbPh}_{3}$ [44].

The IR spectra of $\mathbf{1}$ - $\mathbf{4}$ exhibited four stretching frequencies in the carbonyl region, suggesting a cis-tetracarbonyl system [46] for all four complexes. No distinct pattern is observed for the IR stretching frequencies of $\mathbf{1}-\mathbf{4}$, which are quite similar to carbonyl stretching frequencies of the $\mathrm{PPh}_{3-}$ and $\mathrm{AsPh}_{3}$-subsituted analogue complexes [9-12]. Abel et al. [47] also observed similar 
carbonyl stretching frequencies for $\left[\left(\mathrm{EPh}_{3}\right)_{3}(\mathrm{CO})_{3} \mathrm{Mo}\right]$ with $\mathrm{E}=\mathrm{P}, \mathrm{As}, \mathrm{Sb}$, and therefore proposed that the donor-acceptor properties of $\mathrm{PPh}_{3}, \mathrm{AsPh}_{3}$, and $\mathrm{SbPh}_{3}$ are too similar to cause significant variation in the carbonyl stretching frequencies [48].

\subsection{X-ray structure}

Crystals suitable for single-crystal X-ray diffraction were obtained for $\mathbf{1}, \mathbf{2}$, and $\mathbf{4}$ by vapourdiffusion crystallization using a hexane-dichloromethane (1:1) solvent system. The molecular structures of 1, 2, and 4 are depicted in Figure 3, Figure 4 and Figure 5, respectively. Selected bond lengths, bond angles and torsion angles are given in Table 2. Crystal data and structural refinement parameters for all crystal structures determined are given in the electronic supplementary information.

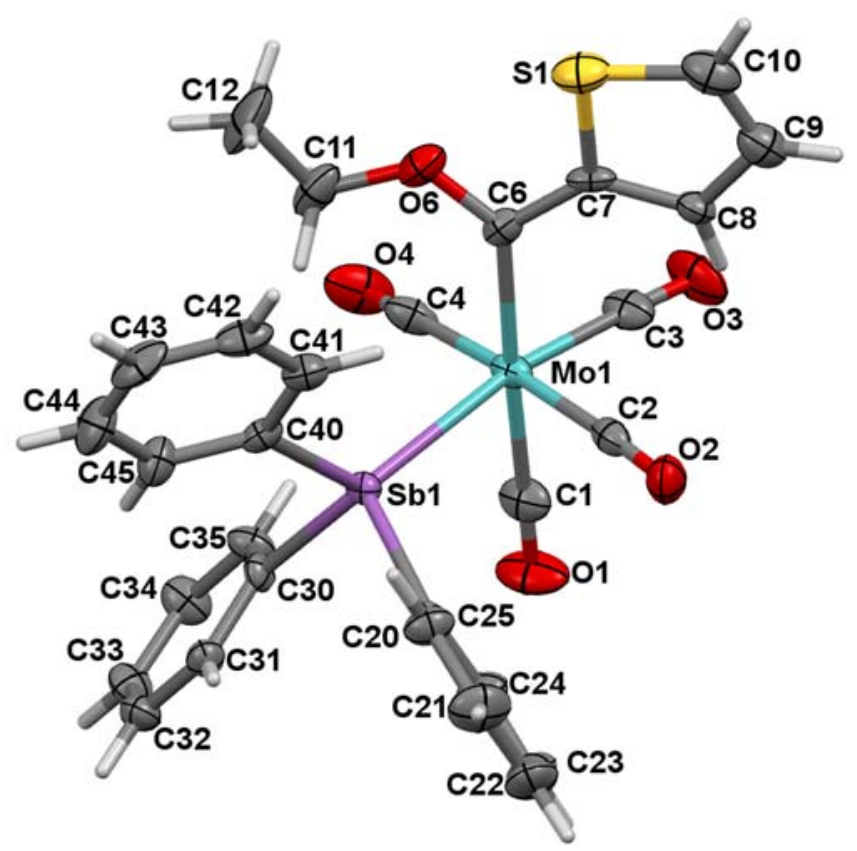

Figure 2. A perspective view of the molecular structure of $\mathbf{1}$, showing the atom numbering scheme. Atomic displacement parameters (ADP's) are shown at the 50\% probability level 


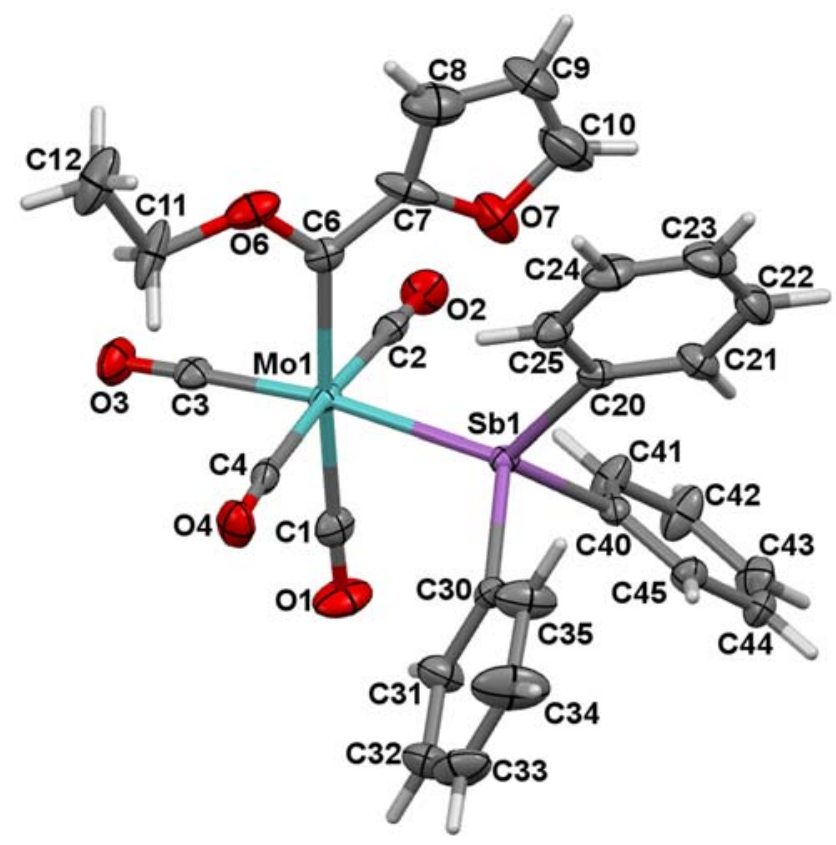

Figure 3. A perspective view of the molecular structure of 2, showing the atom numbering scheme. Atomic displacement parameters (ADP's) are shown at the 50\% probability level

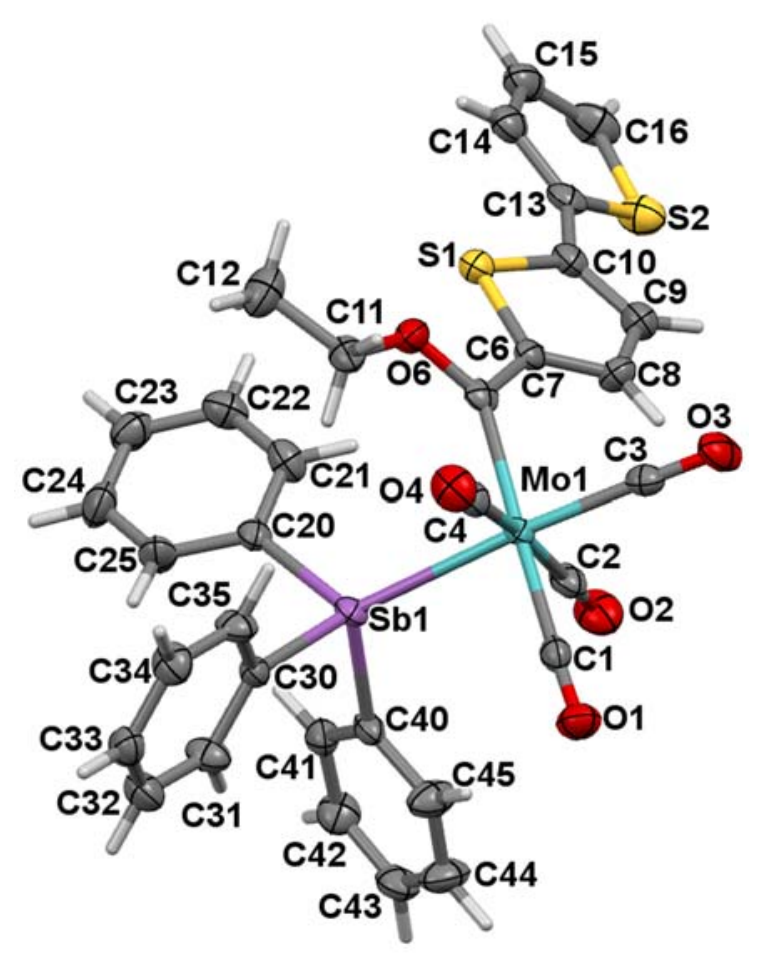

Figure 4. A perspective view of the molecular structure of $\mathbf{4}$, showing the atom numbering scheme. Atomic displacement parameters (ADP's) are shown at the 50\% probability

Table 1. Selected bond lengths $(\AA)$, bond angles $\left({ }^{\circ}\right)$, and torsion angles $\left({ }^{\circ}\right)$ of $\mathbf{1}, \mathbf{2}$, and 4

\begin{tabular}{llll}
\hline & 1 & 2 & 4 \\
\hline Bond length $(\AA)$ & & & \\
\hline
\end{tabular}




\begin{tabular}{lrrr}
\hline Mo1-Sb1 & $2.7552(9)$ & $2.761(6)$ & $2.7674(7)$ \\
Mo1-C6 & $2.208(5)$ & $2.180(7)$ & $2.202(6)$ \\
Mo1-C1 & $2.017(5)$ & $2.028(6)$ & $2.020(7)$ \\
Mo1-C2 & $2.039(6)$ & $2.042(7)$ & $2.037(7)$ \\
Mo1-C3 & $1.985(6)$ & $1.974(6)$ & $1.976(7)$ \\
Mo1-C4 & $2.035(6)$ & $2.051(7)$ & $2.073(7)$ \\
C6-C7 & $1.447(7)$ & $1.418(6)$ & $1.461(9)$ \\
C6-O6 & $1.337(6)$ & $1.327(6)$ & $1.347(7)$ \\
Bond angle ( ${ }^{\circ}$ & & & \\
C6-Mo1-Sb1 & $99.83(12)$ & $93.9(3)$ & $92.39(15)$ \\
C7-C6-Mo & $124.1(3)$ & $124.7(4)$ & $123.8(4)$ \\
O6-C6-Mo & $130.6(4)$ & $130.3(3)$ & $130.1(4)$ \\
O6-C6-C7 & $105.3(4)$ & $105.0(4)$ & $106.1(5)$ \\
C1-Mo1-C6 & $177.5(2)$ & $175.26(14)$ & $178.8(2)$ \\
C2-Mo1-C4 & $175.6(2)$ & $176.22(13)$ & $172.0(3)$ \\
C3-Mo1-Sb1 & $170.16(16)$ & $172.49(10)$ & $172.94(18)$ \\
Torsion angle ( $\left.{ }^{\circ}\right)$ & & & \\
O6-C6-C7-X & $7.1(5)$ & $-177.6(3)$ & $-16.7(6)$ \\
C7-C8-C9-C10 & $0.3(7)$ & $-1.3(6)$ & $-0.6(8)$ \\
Mo1-C6-C7-X & $-174.1(2)$ & $2.0(5)$ & $161.4(3)$ \\
C11-O6-C6-Mo1 & $2.4(6)$ & $-4.9(5)$ & $0.8(8)$ \\
S1-C10-C13-S2 & - & - & $-160.7(4)$ \\
\hline${ }^{a}$ X =S1 (1), X = O7 (2), X = S1(4), & & \\
\hline
\end{tabular}

The longest bond in 1, 2, and 4 is the Mo1-Sb1 bond, with an average length of 2.761(4) A. This value is quite close to the $\mathrm{Mo}-\mathrm{Sb}$ bond in $\left[\left(\mathrm{SbPh}_{3}\right)(\mathrm{CO})_{5} \mathrm{Mo}\right]$, which is reported as $2.756 \AA$ [41]. The metal-carbene bond (Mo1-C6) length for all three complexes is, on average, 2.197(5) $\AA$, and is longer than the metal-carbonyl bond lengths. The longest Mo-CO bond is observed for the carbonyl ligands that are trans to one another (Mo1-C2 and Mo1-C4), while carbonyl ligand trans to the triphenylstibine ligand has the shortest Mo-CO bond length (Mo1-C3). Mo-CO bond length for the carbonyl ligand trans to the Fischer carbene ligand is of intermediary length (Mo1-C1). These Mo$\mathrm{CO}$ bond lengths in 1, 2 and 4 which increase accordingly: $\mathrm{L}=\mathrm{CO}>\mathrm{L}=\mathrm{C}(\mathrm{OR})\left(\mathrm{R}^{\prime}\right)>\mathrm{L}=\mathrm{SbPh}_{3}$ [44], correlate inversely with donor-acceptor properties of the ligand L trans to the carbonyl ligand. The C6-Mo1-Sb1 bond angles are in the region of $90^{\circ}$, indicating a cis-orientation for the carbene and pnictogen ligands. This correlates with the three carbonyl signals observed on the ${ }^{13} \mathrm{C}$ NMR spectrum of $\mathbf{1}$, as well as with the four carbonyl stretching frequencies observed on the IR spectra of all four complexes. Due to the bulkiness of the cis-orientated carbene and stibine ligands, a distorted octahedral geometry is observed. This is indicated by the C6-Mo1-Sb1 bond angles that are slightly larger than the ideal value of $90^{\circ}$, as well as the C1-Mo1-C6, C2-Mo1-C4, and C3-Mo1Sb1 bond angles being approximately $5-11^{\circ}$ smaller than the ideal value of $180^{\circ}$. Steric strain is also observed in the bond angles around the carbene carbon (C6). A trigonal planar geometry is expected for the $\mathrm{sp}^{2}$-hybridized carbene carbon, with ideal bond angles of $120^{\circ}$. The C7-C6-Mo1 and O6-C6-Mol bond angles are larger than $120^{\circ}$, while the $\mathrm{C} 7-\mathrm{C} 6-\mathrm{O} 6$ bond angles are smaller than $120^{\circ}$. In cis- $\left[\left(\mathrm{EPh}_{3}\right)(\mathrm{CO})_{4} \mathrm{MoC}(\mathrm{OEt})\left(\mathrm{C}_{4} \mathrm{H}_{3} \mathrm{~S}\right)\right]$ and $c i s-\left[\left(\mathrm{EPh}_{3}\right)(\mathrm{CO})_{4} \mathrm{MoC}(\mathrm{OEt})\left(\mathrm{C}_{4} \mathrm{H}_{3} \mathrm{O}\right)\right](\mathrm{E}=\mathrm{P}, \mathrm{As}$, $\mathrm{Sb})$, the C7-C6-Mo1, O6-C6-Mo1, and C7-C6-O6 bond angles do not differ significantly [9,12]. 
The O6-C6-C7-O7 torsion angle of $2\left(-177.6(3)^{\circ}\right)$ represents an anti-orientation of the 2-furyl ring with respect to the ethoxy group, while the O6-C6-C7-S1 torsion angles of $1\left(7.1(5)^{\circ}\right)$ and 4 ($\left.16.7(6)^{\circ}\right)$ suggest a syn orientation of the heteroarene ring with respect to the ethoxy group. C7-C8C9-C10 torsion angles close to $0^{\circ}$ confirm planarity of the heterocycles. Furthermore, the two thienyl rings in 4 deviate from planarity by $19^{\circ}$, as the S1-C10-C13-S2 torsion angle has a value of $160.7(4)^{\circ}$. This deviation appears to be similar for all substituted Fischer carbene complexes of 2,2'bithiophene, as the $\mathrm{S} 1-\mathrm{C} 10-\mathrm{C} 13-\mathrm{S} 2$ torsion angle in $c i s-\left[\left(\mathrm{PPh}_{3}\right)(\mathrm{CO})_{4} \mathrm{MoC}(\mathrm{OEt})\left(\mathrm{C}_{8} \mathrm{H}_{5} \mathrm{~S}_{2}\right)\right][12]$, cis$\left[\left(\mathrm{AsPh}_{3}\right)(\mathrm{CO})_{4} \mathrm{MoC}(\mathrm{OEt})\left(\mathrm{C}_{8} \mathrm{H}_{5} \mathrm{~S}_{2}\right)\right] \quad[12]$, and $c i s-\left[\left(\mathrm{AsPh}_{3}\right)(\mathrm{CO})_{4} \mathrm{WC}(\mathrm{OEt})\left(\mathrm{C}_{8} \mathrm{H}_{5} \mathrm{~S}_{2}\right)\right]$ [42] are $163.93(9)^{\mathrm{o}},-163.2(3)^{\mathrm{o}}$, and $-162.21(16)^{\mathrm{o}}$, respectively. Planarity between the carbene substituents and the metal-carbene bond is required for orbital overlap [49]. The ethoxy substituent exhibits good planarity for all three complexes, as the C11-O6-C6-Mo1 torsion angles have values of $4.9(5)^{\circ}$ or less. The 2-thienyl (1) and 2-furyl (2) rings are co-planar with the metal-carbene bond, with Mo1-C6-C7-S1/O7 torsion angles of $-174.1(2)^{\circ}$ and $2.0(5)^{\circ}$, respectively. The 2,2'-bithienyl substituent (4) exhibits poorer planarity with the metal-carbene bond than the 2-thienyl and 2-furyl analogues, as the Mo1-C6-C7-S1 torsion angle is 161.4(3) .

\subsection{X-ray photoelectron spectroscopy}

X-ray photoelectron spectroscopy XPS is a surface analysis technique used to analyse the top 5 - 10 $\mathrm{nm}$ of a sample. It is very useful to gain information such as the elements present, ratios of the different elements (given as an atomic percentage), oxidation state of metals [50], the chemical environment of the metal [50], as well as charge transfer from ligand to metal and vice versa of samples [51]. Since the oxidation state of the metal in $\mathbf{1 - 4}$ are all zero, the difference in the binding energies of the Mo $3 \mathrm{~d}_{5 / 2}$ photoelectron lines of these four complexes will also give insight into the chemical and electronic environment of the Mo metal centre due to the different ligands attached to the metal.

\subsubsection{XPS photoelectron lines (initial state effect)}

Evaluation of the XPS data obtained of $\mathbf{1}$ - $\mathbf{4}$ reveals the presence of carbon C 1s, oxygen O 1s, the

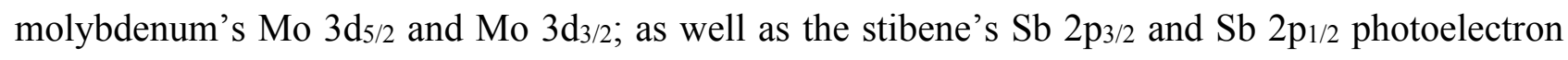
lines, see Table 2 and Figure 5. In addition to these peaks, 1 and $\mathbf{4}$ showed the sulphur S 2p photoelectron lines, while 3 had an additional nitrogen N 1 s photoelectron line. The correct atomic ratio of 1:1 was obtained between $\mathrm{Mo}$ and $\mathrm{Sb}$ for $\mathbf{1}-\mathbf{4}$. 

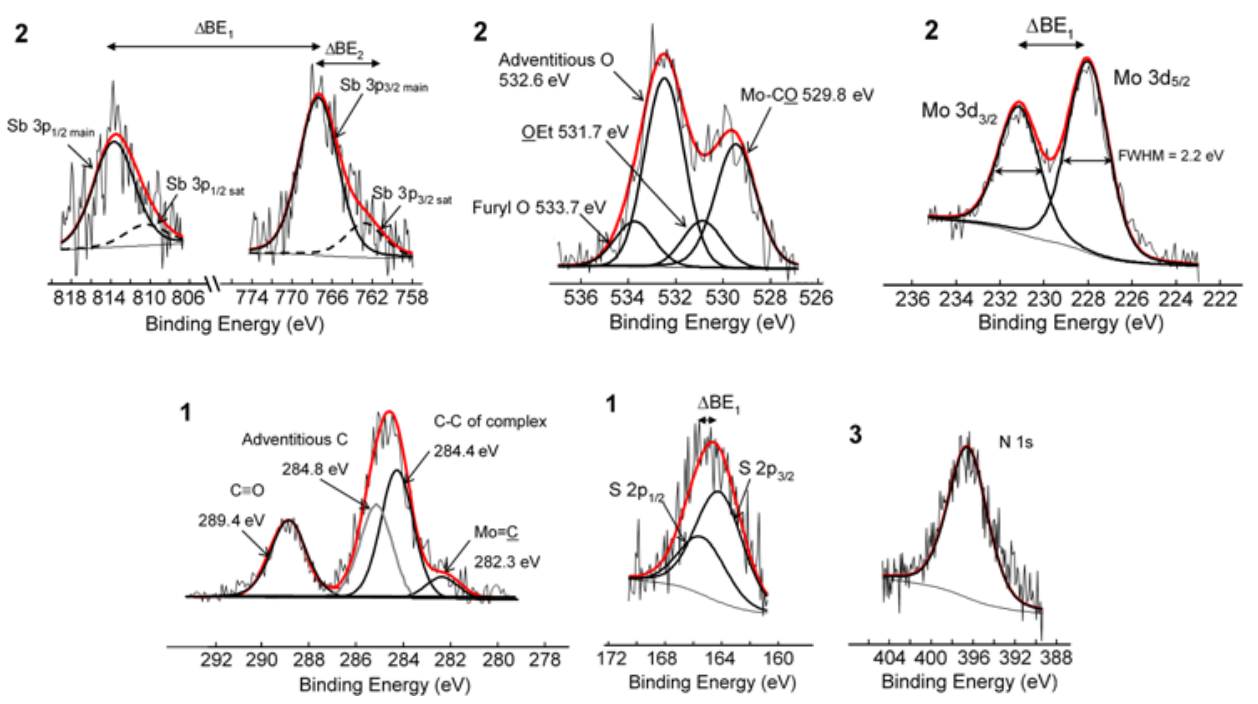

Figure 5. Top: The $\mathrm{Sb} 3 \mathrm{p}, \mathrm{O} 1 \mathrm{~s}$ and Mo $3 \mathrm{~d}$ areas of 2. Bottom: The $\mathrm{C} 1 \mathrm{~s}$ and $\mathrm{S} 2 \mathrm{p}$ area of 1 as well as the $\mathrm{N} 1 \mathrm{~s}$ area of 3.

Table 2. Selected XPS data for 1 - 4: Binding energies of the C 1s carbene carbon, the O 1s carbonyl oxygen, the main Mo $3 \mathrm{~d}_{5 / 2}$ and $3 \mathrm{~d}_{3 / 2}$ photoelectron lines as well as the spin orbit splitting between them $\left(\Delta \mathrm{BE}_{1}=\mathrm{BE}_{\mathrm{Mo} 3 \mathrm{~d} 5 / 2}-\mathrm{BE}_{\mathrm{Mo} 3 \mathrm{~d} 3 / 2}\right)$. The main $\mathrm{Sb} 3 \mathrm{p}_{3 / 2}$ with the spin orbit splitting between the $\mathrm{Sb} 3 \mathrm{p}_{3 / 2}$ and $\mathrm{Sb} 3 \mathrm{p}_{1 / 2}\left(\Delta \mathrm{BE}_{1}=\mathrm{BE}_{\mathrm{Sb} 3 \mathrm{p} 3 / 2}-\mathrm{BE} \mathrm{Sb} 3 \mathrm{p} 1 / 2_{2}\right)$, the binding energy of the satellite $\mathrm{Sb} 3 \mathrm{p}_{3 / 2}$ photoelectron lines and the \% ratio between the intensities of the Sb satellite $3 \mathrm{p}_{3 / 2}$ and main $\mathrm{Sb} 3 \mathrm{p}_{3 / 2}$ photoelectron lines $\left(I_{\text {ratio }}=I_{\mathrm{Sb} 3 \mathrm{p} 3 / 2 \text { sat }} / I_{\mathrm{Sb} 3 \mathrm{p} 3 / 2 \text { main }}\right)$. All binding energy values are given in eV.

\begin{tabular}{cllllllllll}
\hline Complex & $\begin{array}{l}\mathrm{Mo}=\mathrm{C} \\
1 \mathrm{~s}\end{array}$ & $\mathrm{O}$ & $\mathrm{X}$ & $\mathrm{Mo}$ & & & $\mathrm{Sb}$ & & & \\
$2 \mathrm{~s}$ & $\mathrm{p}_{3 / 2}$ & $3 \mathrm{~d}_{5 / 2}$ & $3 \mathrm{~d}_{3 / 2}$ & $\Delta \mathrm{BE}_{1}$ & $3 \mathrm{p}_{3 / 2 \text { main }}$ & $\Delta \mathrm{BE}_{1}$ & $3 \mathrm{p}_{3 / 2 \text { sat }}$ & $I_{\text {ratio }}$ \\
\hline $\mathbf{1}$ & 282.30 & 530.06 & $\begin{array}{l}164.18 \\
(\mathrm{~S} 2 \mathrm{p})\end{array}$ & 228.17 & 231.13 & 2.96 & 767.05 & 46.45 & 762.15 & 0.23 \\
$\mathbf{2}$ & 282.28 & 529.77 & $\begin{array}{l}533.71 \\
(\mathrm{O} 1 \mathrm{~s})\end{array}$ & 227.95 & 231.08 & 3.13 & 767.36 & 46.24 & 762.77 & 0.39 \\
$\mathbf{3}$ & 282.29 & 529.98 & $\begin{array}{l}396.61 \\
(\mathrm{~N} \mathrm{1s})\end{array}$ & 227.61 & 231.36 & 3.82 & 767.63 & 45.67 & 764.34 & 0.49 \\
$\mathbf{4}$ & 282.31 & 529.77 & $\begin{array}{l}163.92 \\
(\mathrm{~S} 2 \mathrm{p})\end{array}$ & 228.05 & 230.89 & 2.84 & 767.35 & 46.43 & 764.75 & 0.42 \\
\hline
\end{tabular}

The binding energy of the photoelectron line of the simulated $\mathrm{C} 1 \mathrm{~s}$ peak of the adventitious carbon (representing the carbons involved in carbon-carbon bonds), which are normally present on samples, are set (shifted) to be located at $284.8 \mathrm{eV}$ (this can be considered as an "internal standard" to ensure that the binding energies of the other elements can be compared for different samples). Additional important carbon peaks that were simulated to fit into the measured photoelectron lines, of 1 - 4, are the carbene carbon (at ca. $282.3 \mathrm{eV}$ ), and the carbonyl carbon (at ca. $289.4 \mathrm{eV}$ ), see Figure 5. The adventitious oxygen found in samples $\mathbf{1}-\mathbf{4}$ were located at ca. $532.6 \mathrm{eV}$, while the oxygen of the ethoxy group were found at ca. $531.7 \mathrm{eV}$ and the carbonyl oxygen were measured to be ca. $529.8 \mathrm{eV}$. These assignments of the carbonyl oxygens were made in correlation with published results that show $\mathrm{C}-\underline{\mathrm{O}}$ to be at the highest binding energy $(533.2 \mathrm{eV})$, followed by $\mathrm{C}=\underline{\mathrm{O}}$ 
(531.3 eV) [52], and $\mathrm{C} \equiv \underline{\mathrm{O}}$ at the lowest binding energy $(530.0 \mathrm{eV})$ [53]. For 2 the $\mathrm{O} 1 \mathrm{~s}$ peak of the furyl moiety is fitted at $533.71 \mathrm{eV}$, see Figure 6, which is within the range where the $\mathrm{O} 1 \mathrm{~s}$ photoelectron line of furan is expected $(532.8-534.1 \mathrm{eV})$ [54]. The sulfur $\mathrm{S} 2 \mathrm{p}_{3 / 2}$ photoelectron lines of the 2-thienyl moieties of $\mathbf{1}$ and $\mathbf{4}$ were found at 164.2 and $163.9 \mathrm{eV}$ respectively, with a spin orbit splitting of $c a .1 .2 \mathrm{eV}$ between the $\mathrm{S} 2 \mathrm{p}_{3 / 2}$ and $\mathrm{S} 2 \mathrm{p}_{1 / 2}$ lines. The nitrogen $\mathrm{N} 1 \mathrm{~s}$ photoelectron line of the 2-(N-methyl)pyrrolyl moiety of 3 was located at $396.61 \mathrm{eV}$.

The Mo $3 \mathrm{~d}_{5 / 2}$ photoelectron lines appear in the range of $227.6-228.2 \mathrm{eV}$, depending on the specific heteroaryl substituent. There is a spin orbit splitting of ca. $2.2 \mathrm{eV}$ separating the Mo $3 \mathrm{~d}_{5 / 2}$ and Mo $3 \mathrm{~d}_{3 / 2}$ photoelectron lines, and the simulated fits gave a full width at half maximum (FWHM) of $c a$. $2.2 \mathrm{eV}$ for the photoelectron lines. The order of increasing binding energy of the Mo $3 \mathrm{~d}_{3 / 2}$ photoelectron lines of $\mathbf{1}-\mathbf{4}$ is:

$\mathbf{3}(227.61 \mathrm{eV})<\mathbf{2}(227.95 \mathrm{eV})<\mathbf{4}(228.05 \mathrm{eV})<\mathbf{1}(228.17 \mathrm{eV})$

An increase in binding energy is an indication that the electron density on the Mo metal centre is lowered, i.e. the Mo metal centre in $\mathbf{1}$ is more electron poor compared to the other complexes, $\mathbf{2}-\mathbf{4}$, of this study. The only difference between complexes $\mathbf{1}-\mathbf{4}$ is the aryl group. This indicates that the 2-thienyl group of $\mathbf{1}$ is the least electron donating and that the 2-(N-methyl)pyrrolyl group of 3 the most electron donating. This result is in agreement with the order of ease of oxidation of related $\operatorname{Mo}(0)$ Fischer carbene complexes containing the same aryl groups [61], as well as the electron donation order of pyrrole $>$ furan $>$ thiophene as determined by Hückel calculations [55].

The $\mathrm{Sb} 3 \mathrm{p}_{3 / 2}$ and $\mathrm{Sb} 3 \mathrm{p}_{1 / 2}$ photoelectron lines of the $\mathrm{Sb}$ atom from the triphenylstibine ligand on 1 - 4 were measured, see Figure 6 and for Table 2 the XPS spectra and data of Sb $3 p_{3 / 2}$ photoelectron lines for 1-4. These lines were positioned at $c a$. $767.4 \mathrm{eV}$ and $813.6 \mathrm{eV}$, respectively, and separated by $c a .46 .2 \mathrm{eV}$, the binding energy values and the large spin orbit splitting correlate well with reported data [56]. A satellite structure at a few eV lower than the main $\mathrm{Sb} 3 \mathrm{p}_{3 / 2}$ photoelectron lines can be observed, this peak is due to a shake-down (or shake-off) mechanism. The origin of the peak will be discussed in the next section. 


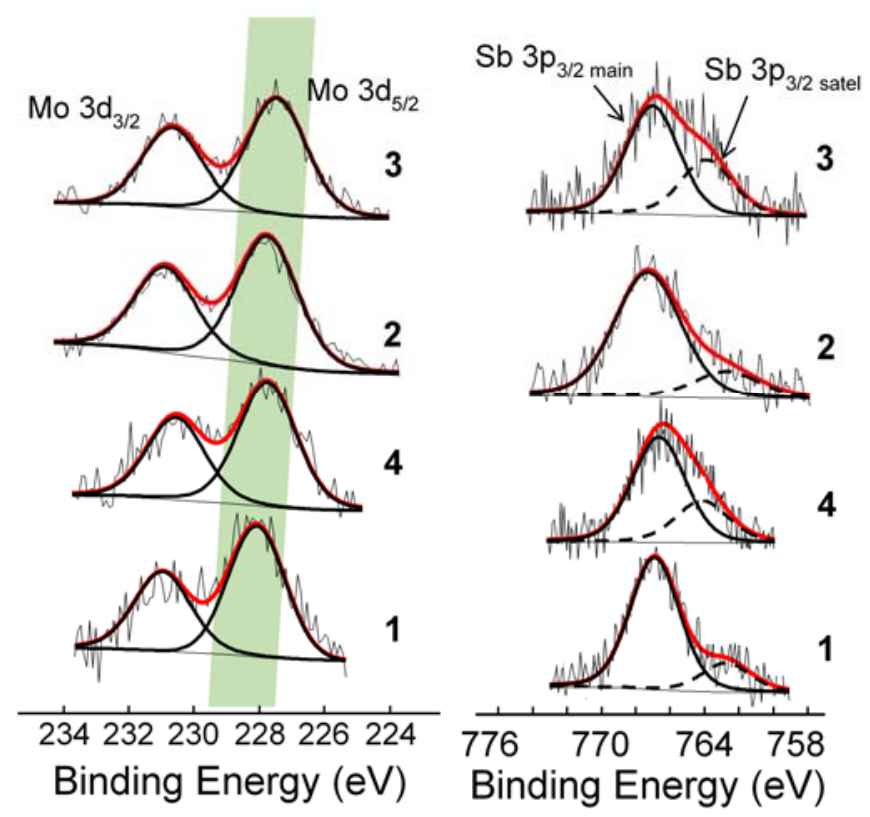

Figure 6. Left: Stacked XPS of Mo 3d area of 1-4, showing the increase in binding energy from top to bottom. Right: Left: Stacked XPS of Sb $3 p$ area of 1-4, the simulated peak indicated with the dashed line is the satellite structure representing the charge transfer during photoionization.

\subsubsection{XPS satellite peaks (final state effect)}

The binding energy position of a main photoelectron line is a result of initial state effects, the specific electronic environment induced by the different ligands (in this case, the heteraryl carbene substituents) [57]. In some cases, a substructure of photoelectron lines (shake-up satellite peaks a few $\mathrm{eV}$ higher than the main line or shake-off satellite peaks a few $\mathrm{eV}$ lower than the main lines), is observed. These satellite peaks are due to final state effects and appear either when the photoelectron imparts energy to another electron of the atom, thereby loosing kinetic energy and appearing at a higher energy in the spectrum [50,57,58], or when a ligand-to-metal or metal-toligand charge transfer occurs during photo-ionization [59]. In the case of ligand-to-metal charge transfer for example, metal shake-up peaks are accompanied by comparable shake-off satellites for the photoelectron lines of the ligand elements, although not commonly observed [60].

The $\mathrm{Sb} 3 p_{3 / 2}$ photoelectron lines showed a shake-off satellite peak (ca. $763.4 \mathrm{eV}$ ) at a few eV lower (ca. $3.9 \mathrm{eV}$ ) than the main $\mathrm{Sb} 3 \mathrm{p}_{3 / 2}$ peaks (ca. $767.3 \mathrm{eV}$ ), see Table 2 for detailed values and Figure 6 Right. This satellite peak was not observed in the $2 \mathrm{p}$ P or $3 \mathrm{~d}$ As photoelectron lines of related triphenylphosphine or triphenylarsine-substituted tetracarbonyl $\operatorname{Mo}(0)$ Fischer carbene complexes [61], so for the first time shake-off satellite peaks observed in the XPS spectra of Mo(0) Fischer carbene complexes is presented here. It is important to note that due to the small spin orbit splitting 
between the Mo 3d photoelectron lines, any attempt to fit a satellite peak to the Mo photoelectron lines would be pointless. In transition metal complexes, satellite peaks located at binding energies that are a few eV lower than the main photoelectron line, are associated with charge transfer from the element under investigation (in this case $\mathrm{Sb}$ ) to the rest of the compound (in this case Mo), and are produced by a shake-off mechanism [50]. The intensity of the satellite peak is indicative of the amount of charge transfer taking place during photoionization [60]. The larger the peak, indicated by $I_{\text {ratio }}$ (which is the ratio of the $\%$ intensity of the satellite peak to the $\%$ intensity of the main peak), the more charge is being donated by the $\mathrm{Sb}$ atom. The order of increasing $I_{\text {ratio, }}$ and by implication the amount of charge transferred (electron density) to the metal from $\mathrm{Sb}$, is:

1; $I_{\text {ratio }}=0.23<2 ; I_{\text {ratio }}=0.39<\mathbf{4} ; I_{\text {ratio }}=0.42<3 ; I_{\text {ratio }}=0.49$

The largest amount of charge transferred from the Sb atom to the metal during photoionization is for complex 3 ( $\left.I_{\text {ratio }}=0.49\right)$.

\subsection{Theoretical calculations}

Different conformations are possible for heteroaryl groups, relative to the ethoxy group, in $\mathbf{1}-\mathbf{4}$, see Figure 7. Thus four conformations are possible for the cis and two for the trans isomers of $\mathbf{1}-\mathbf{3}$, and eight conformations for the cis and four for the trans isomers of 4 . The electronic energies of all the optimized geometries of all the conformers of the cis- and trans-isomers of $\mathbf{1}$ - $\mathbf{4}$ were calculated, and are given in Table 3 . These results show that

(i) the cis-syn conformers are the most stable for 1, $\mathbf{3}$ and 4, while the cis-anti conformers are the most stable for 2 ;

(ii) the carbene ligand is positioned in an staggered conformation, relative to the rest of the ancillary ligands present in the complex;

(iii) the geometry of the crystal structures of 1, 2 and 4 agree with the lowest energy conformations in Table 3 within $0.02 \mathrm{eV}$;

(iv) the energy of all trans conformers are higher than the lowest energy cis conformer;

(v) all anti conformations for $\mathbf{3}$ have a high energy due to the steric interaction between the methyl group of 2-(N-methyl)pyrrolyl and the $\mathrm{CO}$ and/or $\mathrm{SbPh}_{3}$ ligands.

The DFT results in Table 3 are thus in line with the experimental results, as the energeticallyfavoured cis isomer was obtained as the sole substitution product by the synthetic method employed in this study. 
(a)
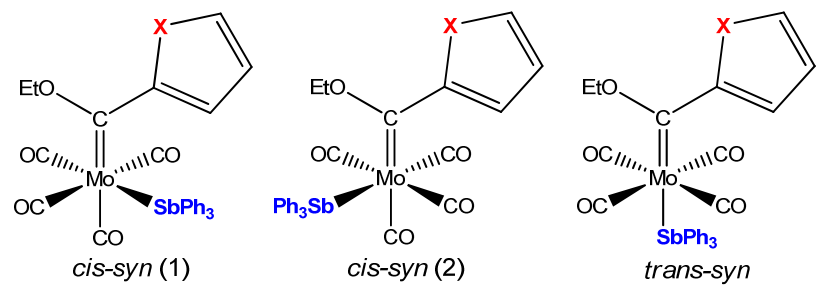<smiles>O=C(O[Na])c1ccccc1[N+](=O)[O-]</smiles>

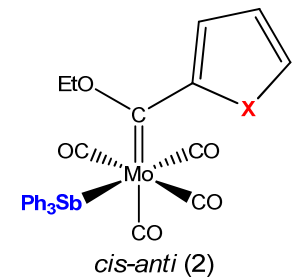<smiles>O=[N+]([O-])[O-]</smiles>

(b)

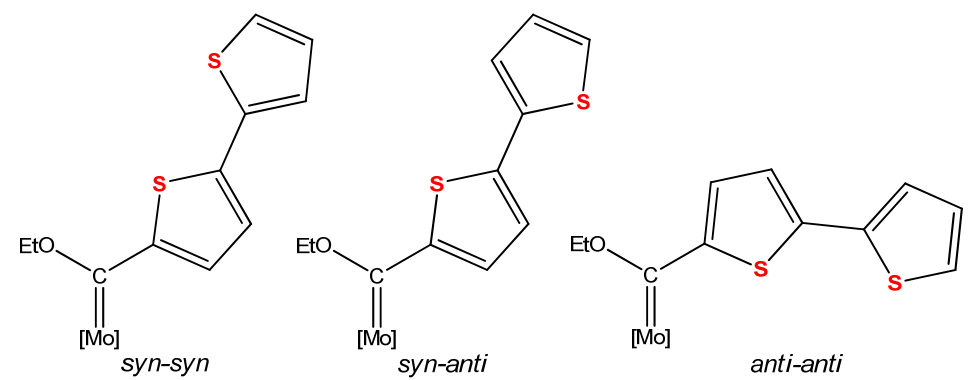<smiles>CCOC(=[W])c1ccc(-c2cccs2)s1</smiles>

Figure 7. (a) Possible conformations and isomers of 1 - 3. (b). Possible conformations of the 2,2-bithienyl moiety in 4, where $[\mathrm{Mo}]=$ cis/trans $-\left[\left(\mathrm{SbPh}_{3}\right)(\mathrm{CO})_{4} \mathrm{Mo}\right]$. Syn and anti refer to the orientation of the heteroaryl heteroatom relative to the ethoxy O-atom, while cis and trans refer to the orientation of the $\mathrm{SbPh}_{3}$ ligand relative to the carbene ligand.

Table 3. Relative energies $(\mathrm{eV})$ of the optimized conformers of the cis and trans isomers of complexes $\mathbf{1}$ - 4. The energy of the lowest energy conformers of each complex is highlighted in bold and the energy of the geometry corresponding to the crystal structure is indicated by an asterisk. Refer to Figure 7 for the possible conformations.

\begin{tabular}{lccc}
\hline & $\mathbf{1}$ & $\mathbf{2}$ & $\mathbf{3}$ \\
\hline cis-anti (1) & 0.13 & $\mathbf{0 . 0 0 *}$ & 0.23 \\
cis-anti (2) & 0.12 & 0.04 & 0.23 \\
cis-syn (1) & $\mathbf{0 . 0 0}$ & 0.11 & $\mathbf{0 . 0 0}$ \\
cis-syn (2) & $\mathbf{0 . 0 1 *}$ & 0.11 & $\mathbf{0 . 0 2}$ \\
trans-anti & 0.16 & 0.07 & 0.30 \\
trans-syn & 0.06 & 0.16 & 0.09 \\
\hline & & $\mathbf{4}$ & \\
\hline cis-anti-anti (1) & & 0.17 & \\
cis-anti-anti (2) & & 0.16 & \\
cis-anti-syn (1) & & 0.11 & \\
cis-anti-syn (2) & & 0.12 & \\
cis-syn-anti (1) & & $\mathbf{0 . 0 0}$ & \\
cis-syn-anti (2) & & $\mathbf{0 . 0 1 *}$ & \\
cis-syn-syn (1) & & $\mathbf{0 . 0 3}$ & \\
cis-syn-syn (2) & & $\mathbf{0 . 0 5}$ & \\
trans-anti-anti & & 0.20 & \\
trans-anti-syn & & 0.17 & \\
trans-syn-anti & & 0.06 & \\
trans-syn-syn & & 0.09 & \\
\hline
\end{tabular}


The DFT energy values obtained in Table 3, as well as literature energy values $[10,12]$, show that for all $\mathrm{Mo}(0)$ Fischer carbene complexes of the type $\left[(\mathrm{L})(\mathrm{CO})_{4} \mathrm{MoC}(\mathrm{OEt})(\mathrm{Ar})\right]$, where $\mathrm{L}=\mathrm{CO}$, $\mathrm{PPh}_{3}, \mathrm{AsPh}_{3}$ or $\mathrm{SbPh}_{3}$, the syn conformers are the most stable for $\mathrm{Ar}=2$-thienyl, 2-(Nmethyl)pyrrolyl or 2,2'-bithienyl, while the anti conformers are the most stable for Ar $=2$-furyl. This result is in agreement with the solid state crystal structures isolated for these complexes $[9,10,12,16]$.

A natural bonding orbital (NBO) analysis of complexes $\mathbf{1}-\mathbf{3}$ showed interactions related to the orientation of the aryl group in $\mathbf{1}-\mathbf{3}$, see Figure 8 . The preference for the anti conformation of the 2-furyl carbene substituent is supported by NBO calculations on 2 (this study) and related complexes [12], all revealing the presence of a stabilizing interaction between the lone pair on the oxygen of the 2-furyl ring and the anti-bonding NBO on a carbonyl ligand present in the complex, with a second order perturbation energy of $2.93 \mathrm{~kJ} \cdot \mathrm{mol}^{-1}$ for 2 (Table 4). This interaction involves the donation of electron density from an electron lone-pair present on the 2-furyl O-atom to an antibonding orbital of the carbonyl ligand, as shown in Figure 8.

The preference for the syn conformation for $\left[(\mathrm{L})(\mathrm{CO}){ }_{4} \mathrm{MoC}(\mathrm{OEt})\left(\mathrm{C}_{4} \mathrm{H}_{3} \mathrm{NMe}\right)\right]$, where $\mathrm{L}=\mathrm{CO}$, $\mathrm{PPh}_{3}, \mathrm{AsPh}_{3}$ or $\mathrm{SbPh}_{3}$, is also supported by NBO calculations for 3 in this study and NBO results on related complexes $\left[(\mathrm{CO})_{5} \mathrm{MoC}(\mathrm{OEt})\left(\mathrm{C}_{4} \mathrm{H}_{3} \mathrm{NMe}\right)\right]$, cis- $\left[\left(\mathrm{PPh}_{3}\right)(\mathrm{CO})_{4} \mathrm{MoC}(\mathrm{OEt})\left(\mathrm{C}_{4} \mathrm{H}_{3} \mathrm{NMe}\right)\right]$, and cis$\left[\left(\mathrm{AsPh}_{3}\right)(\mathrm{CO})_{4} \mathrm{MoC}(\mathrm{OEt})\left(\mathrm{C}_{4} \mathrm{H}_{3} \mathrm{NMe}\right)\right]$ [12]: namely the $\mathrm{LP}(\mathrm{O}) \rightarrow \mathrm{BD} *(\mathrm{C}-\mathrm{H})$ interaction with second order perturbation theory interaction energies as given in Table 4 . The $\mathrm{LP}(\mathrm{O}) \rightarrow \mathrm{BD} *(\mathrm{C}-\mathrm{H})$ interaction involves the ethoxy O-atom and the methyl-group present on the heteroaryl ring. This interaction consisted of electron density donation from an electron lone-pair on the ethoxy O-atom to an empty antibonding orbital of the methyl group of the 2-(N-methylpyrrolyl) moiety; see Figure 8 (c) for the NBO interaction present in 3.

For complex 1, four weak interactions stabilizing the syn conformation of the thienyl group in $\mathbf{1}$,

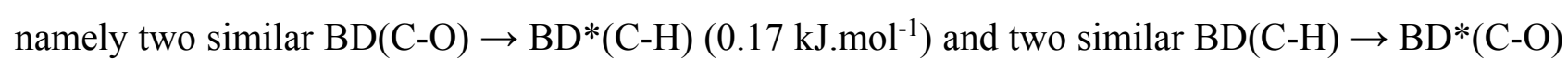
$\left(1.80 \mathrm{~kJ}^{\mathrm{mol}}{ }^{-1}\right)$ interactions, see Figure $8(\mathrm{a})$ for an example of each interaction. 
(a)

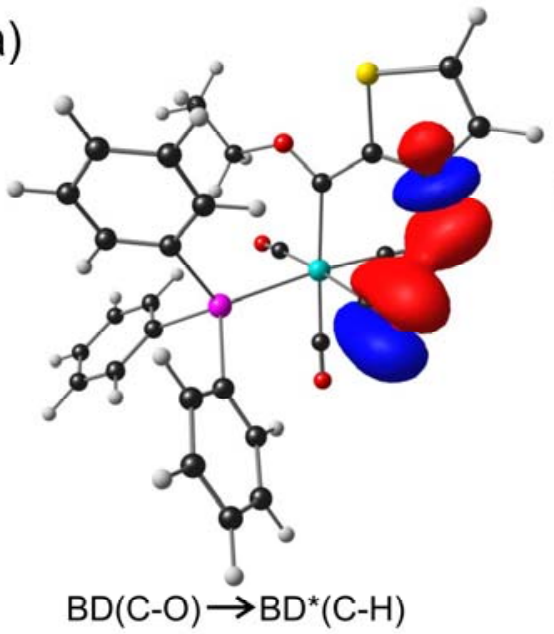

(b)

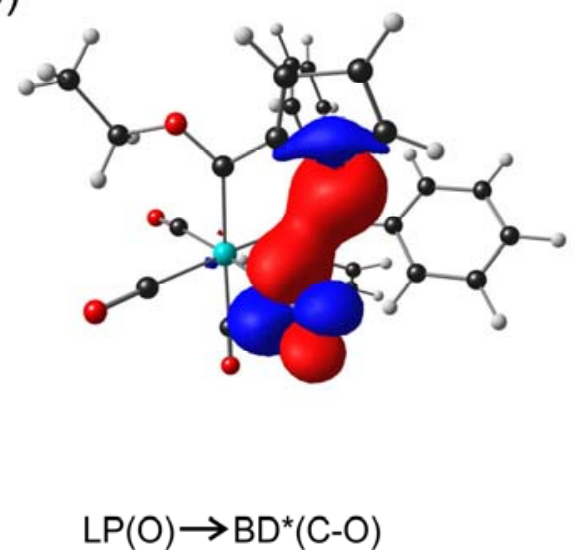

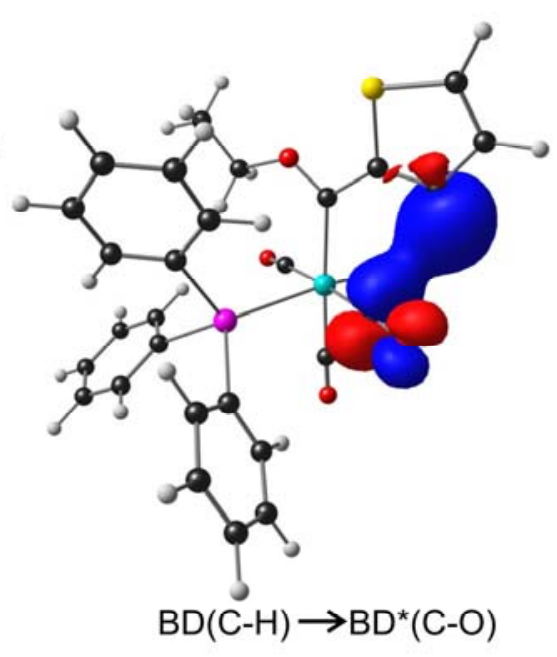

(c)

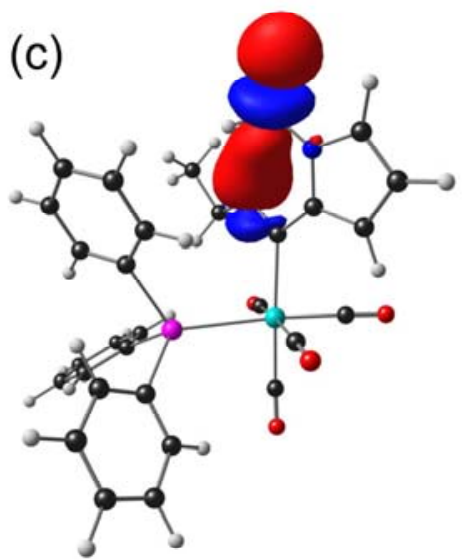

$\mathrm{LP}(\mathrm{O}) \rightarrow \mathrm{BD}^{*}(\mathrm{C}-\mathrm{H})$ (d)
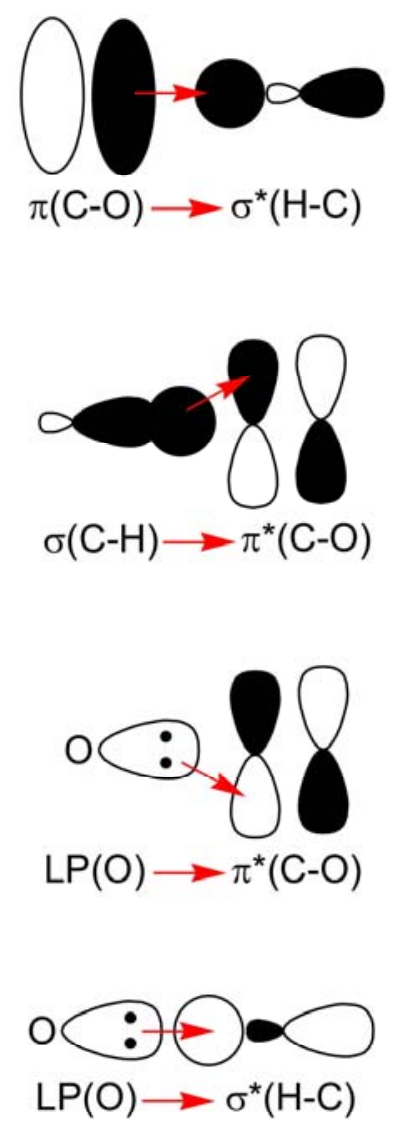

Figure 8. NBO interactions related to the orientation of the aryl ring in (a) 1, (b) 2, (c) 3 and (d) a schematic presentation of the interactions shown in (a) - (c). The natural bond orbital (NBO) plots utilise a contour of $0.05 \mathrm{e} / \AA^{3}$. Colour code (online version): Mo (light blue), Sb (magenta), C (black), S (yellow), N (dark blue), O (red), H (white).

Table 4. Second order perturbation theory interaction energies, E(2) and NBO occupations calculated for the anti conformation of $\left[(\mathrm{L})(\mathrm{CO})_{4} \mathrm{MoC}(\mathrm{OEt})\left(\mathrm{C}_{4} \mathrm{H}_{3} \mathrm{O}\right)\right]$ and the syn conformation of $\left[(\mathrm{L})(\mathrm{CO})_{4} \mathrm{MoC}(\mathrm{OEt})\left(\mathrm{C}_{4} \mathrm{H}_{3} \mathrm{NMe}\right)\right]$ where $\mathrm{L}=\mathrm{CO}, \mathrm{PPh}_{3}, \mathrm{AsPh}_{3}$ or $\mathrm{SbPh}_{3}$.

\begin{tabular}{|c|c|c|c|c|}
\hline & $\mathrm{L}=\mathrm{CO}^{\mathrm{a}}$ & $\mathrm{L}=\mathrm{PPh}_{3}{ }^{\mathrm{a}}$ & $\mathrm{L}=\mathrm{AsPh}_{3}{ }^{\mathrm{a}}$ & $\mathrm{L}=\mathrm{SbPh}_{3}$ \\
\hline \multicolumn{5}{|l|}{$\left[(\mathrm{L})(\mathrm{CO}){ }_{4} \mathrm{MoC}(\mathrm{OEt})\left(\mathrm{C}_{4} \mathrm{H}_{3} \mathrm{O}\right)\right]$} \\
\hline $\mathrm{E}(2) / \mathrm{kJ} \cdot \mathrm{mol}^{-1}$ for $\mathrm{LP}(\mathrm{O}) \rightarrow \mathrm{BD}^{*}(\mathrm{C}-\mathrm{O})$ & 1.88 & 4.18 & 3.97 & 2.09 \\
\hline Occupancy LP/ e & 1.964 & 1.962 & 1.962 & 1.963 \\
\hline Occupancy BD*/e & 0.135 & 0.152 & 0.148 & 0.144 \\
\hline \multicolumn{5}{|l|}{$\left[(\mathrm{L})(\mathrm{CO})_{4} \mathrm{MoC}(\mathrm{OEt})\left(\mathrm{C}_{4} \mathrm{H}_{3} \mathrm{NMe}\right)\right]$} \\
\hline $\mathrm{E}(2) / \mathrm{kJ} \cdot \mathrm{mol}^{-1}$ for $\mathrm{LP}(\mathrm{O}) \rightarrow \mathrm{BD}^{*}(\mathrm{C}-\mathrm{H})$ & 4.85 & 3.81 & 4.02 & 4.64 \\
\hline Occupancy LP/ e & 1.960 & 1.961 & 1.961 & 1.960 \\
\hline Occupancy BD*/e & 0.008 & 0.008 & 0.008 & 0.008 \\
\hline
\end{tabular}

${ }^{a}$ Data from reference [12]. 
Bader's quantum theory of atoms in molecules (QTAIM) theory is presented here for further investigation of the preferred syn conformation for $\mathrm{Ar}=2$-thienyl or 2-(N-methyl)pyrrolyl and the anti conformation for $\mathrm{Ar}=2$-furyl in $\left[(\mathrm{CO})_{5} \mathrm{MoC}(\mathrm{OEt})(\mathrm{Ar})\right]$ and the related tetracarbonyl $\mathrm{Mo}(0)$ Fischer carbene complexes where a $\mathrm{CO}$ ligand is substituted by $\mathrm{PPh}_{3}, \mathrm{AsPh}_{3}$ or $\mathrm{SbPh}_{3}$. $\mathrm{Selected}$ results of the QTAIM analysis on the optimized geometries of both the syn and anti conformations of [(CO) $\left.)_{5} \mathrm{MoC}(\mathrm{OEt})(\mathrm{Ar})\right]$, where $\mathrm{Ar}=2$-thienyl (1a), 2-furyl (2a) or 2-(N-methyl)pyrrolyl (3a), as model complexes for the $\mathrm{SbPh}_{3}$ substituted complexes $\mathbf{1}$ - 3 of this study, as well as the related $\mathrm{PPh}_{3}$ and $\mathrm{AsPh}_{3}$ substituted complexes, are given in Table 5 and illustrated in Figure 9.

Both the syn and anti conformations of 1a - 3a show two similar intramolecular C-H $\cdots$... C interactions that are linked by a QTAIM-determined bond path. Each $\mathrm{C}-\mathrm{H} \cdots \cdot \mathrm{C}$ interaction is between a methylene hydrogen of ethoxy $\left(\mathrm{OCH}_{2} \mathrm{CH}_{3}\right)$ and a carbon of a $\mathrm{CO}$ ligand, with bond path length 2.5 - $2.6 \AA$. These weak intermolecular $\mathrm{C}-\mathrm{H} \cdots \cdot \mathrm{C}$ interactions stabilize the ethoxy group in an anti conformation relative to the heteroaryl group. The electron density $(\rho)$ and the Laplacian of electron density $\left(\nabla^{2} \rho\right)$ at a bond critical points of these bonds paths are 0.008-0.015 e a $0^{-3}$ for $\rho$ and 0.0260.070 e $a_{0}^{-5}$ for $\nabla^{2} \rho$. The latter values compared well with the range determined for hydrogen bonds [62].

Additionally, all complexes also exhibit atom-atom intermolecular interactions between an atom on the heteroaryl group and a carbon of a CO ligand, linked by QTAIM-determined bond paths. For 3a the $\rho$ and $\nabla^{2} \rho$ at a bond critical points of the bond path between a $\mathrm{H}$ atom on the aryl group and a carbon of a CO ligand is larger for the syn conformation than for the anti conformation, in agreement with the preference for a syn conformation for $\left[(\mathrm{CO})_{5} \mathrm{MoC}(\mathrm{OEt})\left(\mathrm{C}_{4} \mathrm{H}_{3} \mathrm{NMe}\right)\right]$, and by implication also for $\left[(\mathrm{L})(\mathrm{CO})_{4} \mathrm{MoC}(\mathrm{OEt})\left(\mathrm{C}_{4} \mathrm{H}_{3} \mathrm{NMe}\right)\right]$ where $\mathrm{L}=\mathrm{PPh}_{3}, \mathrm{AsPh}_{3}$ or $\mathrm{SbPh}_{3}$. The $s y n$ conformation for $\mathbf{3 a}$ is further stabilized by the stronger intramolecular interaction between the carbon of methyl-group of the 2-(N-methyl)pyrrolyl moiety and O-atom of the ethoxy group (see CP \# 52 in Figure 9(c) top).

The anti conformation of 2a is stabilized by the $\mathrm{O} \cdots \mathrm{C}$ intermolecular interaction between $\mathrm{O}$ on the 2-furyl group and a carbon of a CO ligand (CP \# 51 and 52 in Figure 9(b) bottom). The syn conformation of 2a is stabilized by the $\mathrm{H} \cdots \cdot \mathrm{C}$ intermolecular interaction between $\mathrm{H}$ on the 2-furyl group and a carbon of a CO ligand (CP \# 41 and 42 in Figure 9(b) top). The $\rho$ and $\nabla^{2} \rho$ values at the bond critical points CP \# 51 and 52 of the anti conformation is larger than the $\rho$ and $\nabla^{2} \rho$ values at the bond critical points CP \# 41 and 42 of the syn conformation (Table 5), favouring the anti conformation of $\mathbf{2 a}$. 
For 1a, the $\rho$ and $\nabla^{2} \rho$ values at the bond critical points of the $\mathrm{S}_{\mathrm{Th}} \cdots \mathrm{C}_{\mathrm{CO}}$ intermolecular interaction

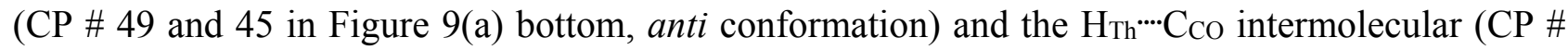
30 and 32 in Figure 9(a) top, syn conformation) are very similar, not unambiguously favouring the experimentally observed syn conformation.

(a)

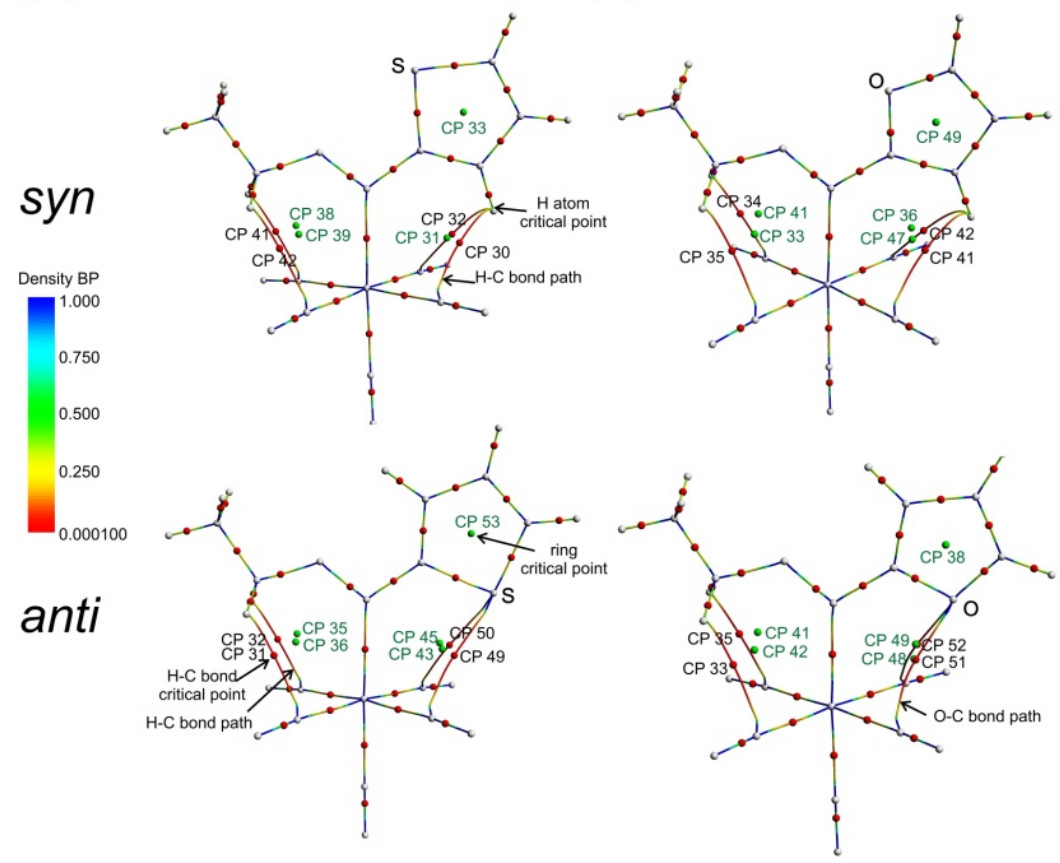

(c)
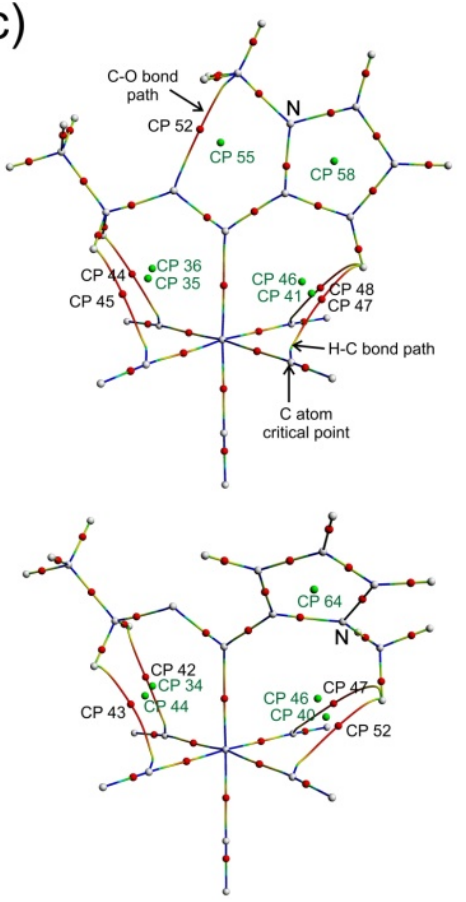

Figure 9: Schematic representation of the critical points (CP) and bond paths (BP) present in the DFT optimised geometry of the most stable syn and anti conformers of [(CO) $\left.{ }_{5} \mathrm{MoC}(\mathrm{OEt})(\mathrm{Ar})\right]$, where $\operatorname{Ar}=2$-thienyl (a), 2-furyl (b) or 2-(N-methyl)pyrrolyl (c). The colour scheme (online version) used for the critical points is as follows: white for an atom CP; red for a bond CP; green for a ring $\mathrm{CP}$. The colour range of the $\mathrm{BP}$ decreases from blue to red, according to the value of the electron density from blue to red as indicated.

Table 5. Topological parameters of the intramolecular bonds the syn and anti conformation in $\left[(\mathrm{CO})_{5} \mathrm{MoC}(\mathrm{OEt})(\mathrm{Ar})\right]$ for $\mathrm{Ar}=2$-thienyl, 2-furyl, or 2-(N-methyl)pyrrolyl. The critical point $(\mathrm{CP})$ numbers are shown in Figure 9.

\begin{tabular}{|c|c|c|c|c|c|c|c|c|}
\hline \multirow{2}{*}{$\begin{array}{l}\text { Bond } \\
\text { critical } \\
\text { point }\end{array}$} & \multirow{2}{*}{$\begin{array}{l}\text { Atoms } \\
\text { involved }^{\text {a }}\end{array}$} & \multirow{2}{*}{$\begin{array}{l}\text { inter- } \\
\text { atomic } \\
\text { distance } \\
/ \AA\end{array}$} & \multirow{2}{*}{$\begin{array}{l}\text { BP } \\
\text { length } \\
/ \AA\end{array}$} & \multicolumn{3}{|c|}{ Eigenvalues of the Hessian matrix } & \multirow{2}{*}{$\begin{array}{l}\text { Electron density } \\
\rho / \mathrm{e} \cdot \mathrm{a}_{0}{ }^{-3}\end{array}$} & \multirow{2}{*}{$\begin{array}{l}\text { Laplacian of } \\
\text { electron } \\
\text { density } \\
\nabla^{2} \rho / \mathrm{e} \cdot \mathrm{a}_{0}{ }^{-5}\end{array}$} \\
\hline & & & & $\lambda_{1} / \mathrm{e} \cdot \mathrm{a}_{0}{ }^{-5}$ & $\lambda_{2} / \mathrm{e} \cdot \mathrm{a}_{0}{ }^{-5}$ & $\lambda_{3} / \mathrm{e} \cdot \mathrm{a}_{0}{ }^{-5}$ & & \\
\hline \multicolumn{9}{|c|}{$\left[(\mathrm{CO})_{5} \mathrm{MoC}(\mathrm{OEt})\left(\mathrm{C}_{4} \mathrm{H}_{3} \mathrm{~S}\right)\right]$ anti } \\
\hline $\mathrm{CP} \# 31$ & $\mathrm{H} 24-\mathrm{C} 4$ & 2.5123 & 2.6224 & $-8.62 \mathrm{E}-03$ & $-4.97 \mathrm{E}-03$ & 4.68E-02 & 0.0101 & 0.0332 \\
\hline CP \# 32 & $\mathrm{H} 23-\mathrm{C} 5$ & 2.5123 & 2.6224 & $-8.62 \mathrm{E}-03$ & $-4.97 \mathrm{E}-03$ & 4.68E-02 & 0.0101 & 0.0332 \\
\hline CP \# 49 & S15-C3 & 3.2374 & 3.3355 & $-4.54 \mathrm{E}-03$ & $-1.87 \mathrm{E}-03$ & $3.43 \mathrm{E}-02$ & 0.0088 & 0.0279 \\
\hline CP \# 50 & $\mathrm{~S} 15-\mathrm{C} 2$ & 3.2374 & 3.3355 & $-4.54 \mathrm{E}-03$ & $-1.87 \mathrm{E}-03$ & $3.43 \mathrm{E}-02$ & 0.0088 & 0.0279 \\
\hline
\end{tabular}


[(CO) $\left.)_{5} \mathrm{MoC}(\mathrm{OEt})\left(\mathrm{C}_{4} \mathrm{H}_{3} \mathrm{~S}\right)\right]$ syn (experimental orientation)

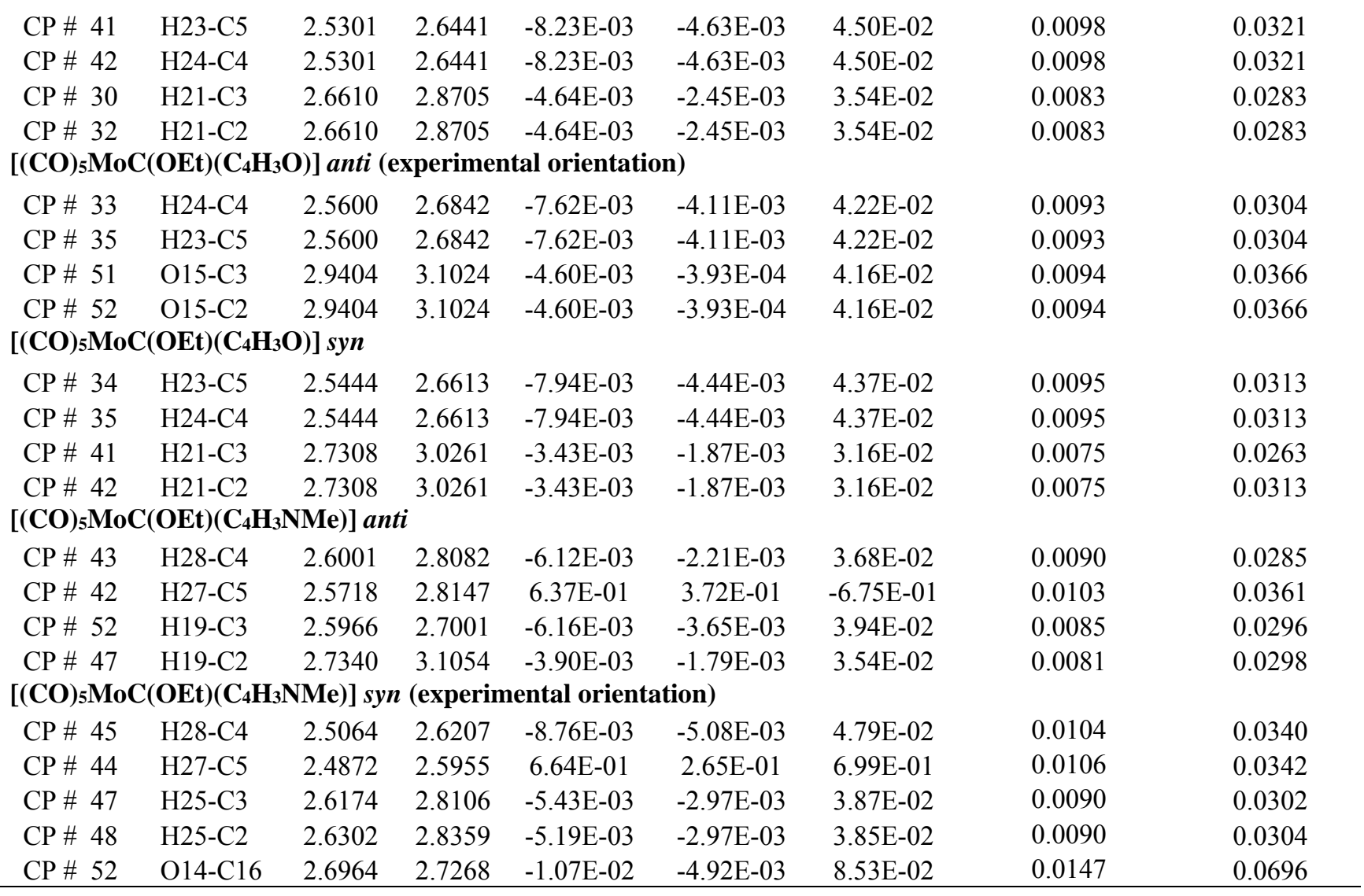

a See Supporting information Figure S1 for atom numbering scheme.

\section{Conclusion}

Experimental solid state crystal data and theoretically calculated geometries for $\operatorname{Mo}(0)$ Fischer carbene complexes of the type $\left[\left(\mathrm{SbPh}_{3}\right)(\mathrm{CO})_{4} \mathrm{MoC}(\mathrm{OEt})(\mathrm{Ar})\right]$ with $\mathrm{Ar}=2$-thienyl (1), 2-furyl (2), 2 (N-methyl)pyrrolyl (3) or 2,2'-bithienyl (4) confirm the preferred cis orientation of the 2-thienyl, 2(N-methyl)pyrrolyl and 2,2'-bithienyl groups relative to the ethoxy group, and the preferred anti orientation of the 2-furyl group relative to the ethoxy group in $\mathbf{1}-\mathbf{4}$. Bonding paths obtained by quantum theory of atoms in molecules (QTAIM) calculations as well as donor-acceptor interactions obtained by natural bonding orbital (NBO) calculations gave support to the preferred orientation of the aryl groups relative to the ethoxy group in $\mathbf{1}-\mathbf{4}$ on a molecular level. The X-ray photoelectron spectroscopy measured binding energy of the Mo 3d $d_{3 / 2}$ photoelectron lines of 1 - 4 increases in the same order as the ease of oxidation of $\operatorname{Mo}(0)$ Fischer carbene complexes containing the same aryl groups $\left[\left(\mathrm{SbPh}_{3}\right)(\mathrm{CO})_{4} \mathrm{MoC}(\mathrm{OEt})(\mathrm{Ar})\right]$, namely $\mathrm{Ar}=(\mathrm{N}$-methyl $)$ pyrrolyl $<2$-furyl $<2$-thienyl $\approx 2,2^{\prime}-$ bithienyl; illustrating the good intramolecular communication between the Mo metal centre and the various ligands attached to the metal in $\mathbf{1}$ - 4 .

\section{Appendix A. Supplementary data}


The optimized coordinates of the DFT calculations, Figure S1 and crystallographic supplementary material can be found in the Supporting Information. CCDC 1538420 - 1538422 contain the supplementary crystallographic data for 1 - 3. These data can be obtained free of charge via http://www.ccdc.cam.ac.uk/conts/retrieving.html, or from the Cambridge Crystallographic Data Centre, 12 Union Road, Cambridge CB2 1EZ, UK; fax: (+44) 1223-336-033; or e-mail: deposit@ccdc.cam.ac.uk.

\section{Disclosure statement}

The authors declare no conflict of interest.

\section{Acknowledgements}

This work has received support from the Norwegian Supercomputing Program (NOTUR, Grant No. NN4654K) (JC), the High Performance Computing facility of the UFS (JC), the South African National Research Foundation (JC, MMC, ML) and the Central Research Fund of the University of the Free State, Bloemfontein (JC, MMC) and the University of Pretoria (ML).

\section{References}

[1] K.H. Dötz, Carbene Complexes in Organic Synthesis [New Synthetic Methods (47)], Angew. Chem., Int. Ed. 23 (1984) 587-608. DOI: 10.1002/anie.198405871.

[2] M.F. Semmelhack, J.J. Bozell, T. Sato, W. Wulff, E. Spiess, A. Zask, The synthesis of nanaomycin A and deoxyfrenolicin by alkyne cycloaddition to chromium-carbene complexes, J. Am. Chem. Soc. 104 (1982) 5850-5852. DOI: 10.1021/ja00385a079.

[3] K.H. Dötz, I Pruskill, Vitamin-synthesen mit carben-komplexen I. synthese der vitamine K3 und K1(20) via pentacarbonyl-[methoxy(phenyl)carben] chrom, J. Organomet. Chem. 209 (1981) C4-C6. DOI: 10.1016/S0022-328X(00)88985-8.

[4] E.O. Fischer, K.H. Dötz, Übergangsmetall-Carben-Komplexe, XIX. Zur Synthese von Cyclopropanderivaten mit Übergangsmetall-Carbonyl-Carben-Komplexen, Chem. Ber. 103 (1970) 1273-1278. DOI: 10.1002/cber.19701030430.

[5] E.O. Fischer. A. Maasböl, Übergangsmetall-Carben-Komplexe, II. Phenylmethoxycarbenund Methylmethoxycarben-pentacarbonyl-chrom, -molybdän, -wolfram und - 
cyclopentadienyl-dicarbonyl-mangan, Chem. Ber. 100 (1967) 2445-2456. DOI: 10.1002/cber.19671000744.

[6] E.O. Fischer R. Aumann, Übergangsmetall-Carben-Komplexe, XI. Über die Darstellung von cis- $\mathrm{M}\left(\mathrm{C}_{6} \mathrm{H}_{5}\right)_{3}-\mathrm{Methoxy}$-organylcarben-metall-tetracarbonyl-Komplexen $(\mathrm{M}=\mathrm{P}, \mathrm{As}, \mathrm{Sb})$ des Chroms, Molybdäns und Wolframs aus den $\mathrm{M}\left(\mathrm{C}_{6} \mathrm{H}_{5}\right)_{3}$-Metall-pentacarbonylen durch $\mathrm{CH}_{3}{ }^{-}$ $/ \mathrm{CH}_{3}{ }^{+}$-Addition, Chem. Ber. 102 (1969) 1495-1503. DOI: 10.1002/cber.19691020509.

[7] E.O. Fischer, H. Fischer, Übergangsmetall-Carben-Komplexe, LXVIII. Synthese von cis- und trans-Tetracarbonyl(carben)(phosphin)-Komplexen von Chrom(0) und Wolfram(0), Chem. Ber. 107 (1974) 657-672. DOI: 10.1002/cber.19741070238.

[8] E.O. Fischer, K. Richter, Übergangsmetall-Carben-Komplexe, LXXXIV: Synthese und Isomerisierung von arsin- und stibinsubstituierten cis und trans-Tetracarbonyl(carben)Komplexen und Darstellung von Pentacarbonyl(trialkylbismutin)-Komplexen von Chrom(0), Chem. Ber. 109 (1976) 1140-1157. DOI: 10.1002/cber.19761090336.

[9] M. Landman, T. Levell, P.H. van Rooyen, J. Conradie, Conformation analysis of triphenylphosphine in trans and cis triphenylphosphine-substituted Fischer carbene complexes J. Mol. Struct. 1065-1066 (2014) 29-38. DOI: 10.1016/j.molstruc.2014.02.014.

[10] M. Landman, T.J. Levell, M.M. Conradie, P.H. van Rooyen, J. Conradie, Structural and conformational study of pentacarbonyl and phosphine substituted Fischer alkoxy- and aminocarbene complexes of molybdenum, J. Mol. Struct. 1086 (2015) 190-200. DOI: 10.1016/j.molstruc.2015.01.022.

[11] M. Landman, T. Levell, B.E. Buitendach, M.M. Conradie, J. Conradie, Effect of CO substitution on the redox properties of Fischer $\mathrm{Mo}(0)$ carbene complexes $\mathrm{Mo}(\mathrm{CO})_{5}=\mathrm{C}(\mathrm{Y})(2-$ Furyl), $\mathrm{Y}=\mathrm{OEt}$, NHCy or $\mathrm{NH}_{2}$, Electrochim. Acta 174 (2015) 282-289. DOI: 10.1016/j.electacta.2015.05.191.

[12] A. Jansen van Rensburg, M. Landman, P.H. van Rooyen, M.M. Conradie, J. Conradie, Molybdenum(0) Fischer ethoxycarbene complexes: Synthesis, X-ray crystal structures and DFT study, Polyhedron, 2017, 121, 285-296. DOI: 10.1016/j.poly.2016.10.013

[13] H. Meerwein, Triethyloxonium tetrafluoroborate, Org. Synth. 46 (1966) 113. DOI: 10.15227/orgsyn.046.0113.

[14] G.H. Spies, R.J. Angelici, Model studies of thiophene hydrodesulfurization using (.eta.thiophene)Ru(.eta.-C5H5)+. Reactions leading to C-S bond cleavage, Organometallics 6 (1987) 1897-1903. DOI: 10.1021/om00152a011. 
[15] W.L.F. Armarego, D.D. Perrin, Purification of laboratory chemicals, Reed Educational and Professional Publishing Ltd., Oxford, 1996.

[16] M. Landman, H. Görls, S. Lotz, Synthesis of Molybdenum Carbene Complexes of Thiophene Derivatives, Z. Anorg. Allg. Chem. 628 (2002) 2037-2043. DOI: 10.1002/15213749(200209)628:9/10<2037::AID-ZAAC2037>3.0.CO;2-T.

[17] APEX2 (including SAINT and SADABS), Bruker AXS Inc., Madison, WI, 2012.

[18] G.M. Sheldrick, A short history of SHELX, Acta Crystallogr. Sect. A: Found. Crystallogr. 64 (2008) 112-122. DOI: 10.1107/S0108767307043930.

[19] L.G. Farrugia, ORTEP-3 for Windows - a version of ORTEP-III with a Graphical User Interface (GUI), J. Appl. Crystallogr. 30 (1997) 565-566. DOI: 10.1107/S0021889897003117.

[20] A.D. Becke, Density-functional exchange-energy approximation with correct asymptotic behaviour, Phys. Rev. A 38 (1988) 3098-3100. DOI: 10.1103/PhysRevA.38.3098.

[21] C.T. Lee, W.T. Yang, R.G. Parr, Development of the Colle-Salvetti correlation-energy formula into a functional of the electron density, Phys. Rev. B 37 (1988) 785-789. DOI: 10.1103/PhysRevB.37.785.

[22] J. Stephens, F.J. Devlin, C.F. Chabalowski, M.J. Frisch, Ab-Initio Calculation of Vibrational Absorption and Circular-Dichroism Spectra Using Density-Functional Force-Fields, J. Phys. Chem. 98 (1994) 11623-11627. DOI: 10.1021/j100096a001.

[23] M.J. Frisch, G.W. Trucks, H.B. Schlegel, G.E. Scuseria, M.A. Robb, J.R. Cheeseman, G. Scalmani, V. Barone, B. Mennucci, G.A. Petersson, H. Nakatsuji, M. Caricato, X. Li, H.P. Hratchian, A.F. Izmaylov, J. Bloino, G. Zheng, J.L. Sonnenberg, M. Hada, M. Ehara, K. Toyota, R. Fukuda, J. Hasegawa, M. Ishida, T. Nakajima, Y. Honda, O. Kitao, H. Nakai, T. Vreven, J.A. Montgomery (Jr), J.E. Peralta, F. Ogliaro, M. Bearpark, J.J. Heyd, E. Brothers, K.N. Kudin, V.N. Staroverov, T. Keith, R. Kobayashi, J. Normand, K. Raghavachari, A. Rendell, J.C. Burant, S.S. Iyengar, J. Tomasi, M. Cossi, N. Rega, J.M. Millam, M. Klene, J.E. Knox, J.B. Cross, V. Bakken, C. Adamo, J. Jaramillo, R. Gomperts, R.E. Stratmann, O. Yazyev, A.J. Austin, R. Cammi, C. Pomelli, J.W. Ochterski, R.L. Martin, K. Morokuma, V.G. Zakrzewski, G.A. Voth, P. Salvador, J.J. Dannenberg, S. Dapprich, A.D. Daniels, O. Farkas, J.B. Foresman, J.V. Ortiz, J. Cioslowski, D.J. Fox, Gaussian 09, Revision B.01, Gaussian, Inc., Wallingford, CT, 2013.

[24] F. Weigend, R. Ahlrichs, Balanced basis sets of split valence, triple zeta valence and quadruple zeta valence quality for $\mathrm{H}$ to Rn: Design and assessment of accuracy, Phys. Chem. Chem. Phys. 7 (2005) 3297-3305. DOI: 10.1039/B508541A. 
[25] J.P. Foster, F. Weinhold, Natural hybrid orbitals, J. Am. Chem. Soc. 102 (1980) 7211-7218. DOI: $10.1021 / \mathrm{ja} 00544 \mathrm{a} 007$

[26] A.E. Reed, F. Weinhold, Natural localized molecular orbitals, J. Phys. Chem. 83 (1985) 17361740. DOI: $10.1063 / 1.449360$.

[27] A.E. Reed, R.B. Weinstock, F. Weinhold, Natural population analysis, J. Chem. Phys. 83 (1985) 735-746. DOI: 10.1063/1.449486.

[28] A.E. Reed, L.A. Curtiss, F. Weinhold, Intermolecular interactions from a natural bond orbital, donor-acceptor viewpoint, Chem. Rev. 88 (1988) 899-926. DOI: 10.1021/cr00088a005.

[29] NBO 3.1. E.D. Glendening, J.K., Badenhoop, A.E., Reed, J.E., Carpenter, J.A., Bohmann, C.M., Morales, F. Weinhold, Theoretical Chemistry Institute, University of Wisconsin, Madison, WI, 2001.

[30] R.F.W. Bader, A quantum theory of molecular structure and its applications, Chem. Rev. 91 (1991) 893-928. DOI: 10.1021/cr00005a013

[31] F. Cortés-Guzmán, R.F.W. Bader, Complementarity of QTAIM and MO theory in the study of bonding in donor-acceptor complexes, Coord. Chem. Rev. 249 (2005) 633-662. DOI: 10.1016/j.ccr.2004.08.022

[32] J.I. Rodríguez, R.F.W. Bader, P.W. Ayers, C. Michel, A.W. Götz, C. Bo, A high performance grid-based algorithm for computing QTAIM properties, Chem. Phys. Lett. 472 (2009) 149152. DOI: $10.1016 / j . c p l e t t .2009 .02 .081$

[33] G. te Velde, F.M. Bickelhaupt, S.J.A. van Gisbergen, C.F. Guerra, E.J. Baerends, J.G. Snijders, T. Ziegler, Chemistry with ADF, J. Comput. Chem. 22 (2001) 931-967. DOI: $10.1002 /$ jcc. 1056

[34] C. Fonseca Guerra, J.G. Snijders, G. te Velde and E.J. Baerends, Towards an order-N DFT method, Theor. Chem. Acc. 99 (1998) 391-403. DOI: 10.1007/s002140050353

[35] ADF 2013, SCM, Theoretical Chemistry, Vrije Universiteit, Amsterdam, The Netherlands, 2013 (available online at http://www.scm.com).

[36] F. Moulder, W.F. Stickle, P.E. Sobol, K.D. Bomben, Handbook of X-ray Photoelectron Spectroscopy, ULVAC-PHI, Inc., Enzo, Chigasaki, Japan, (1995).

[37] E.O. Fischer, A. Maasböl, On the Existence of a Tungsten Carbonyl Carbene Complex, Angew. Chem., Int. Ed. 3 (1964) 580-581. DOI: 10.1002/anie.196405801

[38] M. Landman, R. Pretorius, R. Fraser, B.E. Buitendach, M.M. Conradie, P.H. van Rooyen, and J. Conradie, Electrochemical behaviour and structure of novel phosphine- and phosphite- 
substituted tungsten(0) Fischer carbene complexes, Electrochim. Acta 130 (2014) 104-118. DOI: 10.1016/j.electacta.2014.02.127.

[39] C.N. Matthews, T.A. Magee, J.H. Wotiz, Organic Derivatives of Chromium, Molybdenum and Tungsten Carbonyls, J. Am. Chem. Soc. 81 (1959) 2273-2274. DOI: 10.1021/ja01476a008.

[40] A. Arrieta, F.P. Cossío, I. Fernández, M. Gómez-Gallego, B. Lecea, M.J. Mancheño, M.A. Sierra, A Theoretical-Experimental Approach to the Mechanism of the Photocarbonylation of Chromium(0) (Fischer)-Carbene Complexes and Their Reaction with Imines, J. Am. Chem. Soc. 122 (2000) 11509-11510. DOI: 10.1021/ja000706t.

[41] M.J. Aroney, I.E. Buys, M.S. Davies T.W. Hambley, Crystal structures of [W(CO)s $\left(\mathrm{PPh}_{3}\right)$ ], $\left[\mathrm{M}(\mathrm{CO})_{5}\left(\mathrm{AsPh}_{3}\right)\right]$ and $\left[\mathrm{M}(\mathrm{CO})_{5}\left(\mathrm{SbPh}_{3}\right)\right](\mathrm{M}=\mathrm{Mo}$ or $\mathrm{W})$ : a comparative study of structure and bonding in $\left[\mathrm{M}(\mathrm{CO})_{5}\left(\mathrm{EPh}_{3}\right)\right]$ complexes $(\mathrm{E}=\mathrm{P}$, as or $\mathrm{Sb} ; \mathrm{M}=\mathrm{Cr}$, Mo or W) J. Chem. Soc., Dalton Trans (1994) 2827-2834. DOI: 10.1039/DT9940002827.

[42] A. Jansen van Rensburg, M. Landman, P.H. van Rooyen, M.M. Conradie, J. Conradie, Synthesis and structure of novel triphenylarsine-substituted tungsten(0) Fischer carbene complexes, J. Mol. Struct. 1105 (2016) 205-213. DOI: 10.1016/j.molstruc.2015.10.012.

[43] L. Lancelotti, R. Tubino, S. Luzzati, E. Licandro, S. Maiorana, A. Papagni, Spectroscopy of transition-metal substituted oligothiophenes, Synth. Met. 93 (1998) 27-32. DOI: 10.1016/S0379-6779(98)80128-8.

[44] P.S. Braterman, D.W. Milne, E.W. Randall, E. Rosenberg, Carbon-13 nuclear magnetic resonance spectra of tungsten and molybdenum carbonyl derivatives, J. Chem. Soc., Dalton Trans. (1973) 1027-1031. DOI: 10.1039/DT9730001027.

[45] W. Buchner, W.A. Schenk, Carbon-13 NMR spectra of monosubstituted tungsten carbonyl complexes. NMR trans influence in octahedral tungsten(0) compounds, Inorg. Chem. 23 (1984) 132-137. DOI: 10.1021/ic00170a004.

[46] P.S Braterman, Metal Carbonyl Spectra, Academic Press Inc., London, 1975.

[47] E.W. Abel, M.A. Bennett, G. Wilkinson, 467. Substituted carbonyl compounds of chromium, molybdenum, tungsten, and manganese, J. Chem. Soc. (1959) 2323-2327. DOI: $10.1039 / J R 9590002323$.

[48] F.A. Cotton, R.M. Wing, The Crystal and Molecular Structure of cis(Diethylenetriamine)molybdenum Tricarbonyl; the Dependence of Mo-C Bond Length on Bond Order, Inorg. Chem. 4 (1965) 314 - 317. DOI: 10.1021/ic50025a012. 
[49] U. Schubert, Structural consequences of bonding in transition metal carbene complexes, Coord. Chem. Rev. 55 (1984) 261-286. DOI: 10.1016/0010-8545(84)85002-X.

[50] J. W. Niemantsverdriet, Spectroscopy in Catalysis, $3^{\text {rd }}$ Ed., John Wiley \& Sons, Weinheim (2007).

[51] F. de Groot, A. Kotani, Core Level Spectroscopy of solids, CRC Press, Boca Raton (2008).

[52] S.A. Abouali, M.A. Garakani, B. Zang, Z.L. Xu, E.K. Heidari, J.q. Huang, J. Huang, J.K. Kim, Electrospun Carbon Nanofibers with in Situ Encapsulated $\mathrm{Co}_{3} \mathrm{O}_{4}$ Nanoparticles as Electrodes for High-Performance Supercapacitors, ACS Appl. Mater. Interfaces 7 (2015) 13503-13511. DOI: 10.1021/acsami.5b02787.

[53] S.J. Atkinson, C.R. Brundle, M.W. Roberts, Ultra-violet and X-ray photoelectron spectroscopy (UPS and XPS) of $\mathrm{CO}, \mathrm{CO}_{2}, \mathrm{O}_{2}$ and $\mathrm{H}_{2} \mathrm{O}$ on molybdenum and gold films, Faraday Discuss. Chem. Soc. 58 (1974) 62-79. DOI: 10.1039/DC9745800062

[54] J.L. Solomon, R.J. Madix, J. Stohr, Orientation and absolute coverage of furan and 2,5dihydrofuran on $\operatorname{Ag}(110)$ determined by near edge x-ray absorption fine structure and x-ray photoelectron spectroscopy, J. Chem. Phys. 94 (1991) 4012-4023. DOI: 10.1063/1.460678.

[55] I.D.L. Albert, T.J. Marks, M.A. Ratner, Large Molecular Hyperpolarizabilities. Quantitative Analysis of Aromaticity and Auxiliary Donor-Acceptor Effects, J. Am. Chem. Soc. 119 (1997) 6575-6582. DOI: 10.1021/ja962968u

[56] X. Ren, X. Zhang, N. Liu, L. Wen, L. Ding, Z. Ma, J. Su, L. Li, J. Han, Y. Gao, White LightEmitting Diode From Sb-Doped p-ZnO Nanowire Arrays/n-GaN Film, Adv. Funct. Mater. 25 (2015) 2182-2188. DOI: 10.1002/adfm.201404316

[57] F.S. Roberts, S.L. Anderson, A.C. Reber, S.N. Khanna, Initial and Final State Effects in the Ultraviolet and X-ray Photoelectron Spectroscopy (UPS and XPS) of Size-Selected $\mathrm{Pd}_{\mathrm{n}}$ Clusters Supported on $\mathrm{TiO}_{2}$ (110), J. Phys. Chem. C 119 (2015) 6033-6046. DOI: $10.1021 / \mathrm{jp} 512263 \mathrm{w}$.

[58] A.P. Grosvenor, B.A. Kobe, M.C. Biesinger, N.S. McIntyre, Investigation of multiplet splitting of Fe 2p XPS spectra and bonding in iron compounds, Surf. Interf. Anal. 2004, 36, 1564-1574. DOI: $10.1002 /$ sia.1984

[59] J.S.H.Q. Perera, D.C. Frost, C.A. McDowell, X-ray photoelectron spectroscopy of Co(II), $\mathrm{Ni}(\mathrm{II})$, and $\mathrm{Cu}(\mathrm{II})$ acetylacetonate vapors, J. Chem. Phys. 72 (1980) 5151-5158. DOI: $10.1063 / 1.439749$. 
[60] B.E. Buitendach, E. Erasmus, J.W. Niemantsverdriet, J.C. Swarts, Properties of Manganese(III) Ferrocenyl- $\beta$-Diketonato Complexes Revealed by Charge Transfer and Multiplet Splitting in the Mn 2p and Fe 2p X-Ray Photoelectron Envelopes, Molecules, 2016, 21, 1427-1442. DOI: 10.3390/molecules21111427.

[61] A. Jansen van Rensburg, M. Landman, E. Erasmus, D. van der Westhuizen, H. Ferreira, M.M. Conradie, J, Conradie, Electrochemical and X-ray photoelectron spectroscopic insights into Molybdenum(0) Fischer ethoxycarbene complexes, Electrochim. Acta 219 (2016) 204-213. DOI: $10.1016 /$ j.electacta.2016.09.143.

[62] U. Koch, P.L.A. Popelier, Characterization of C-H-O Hydrogen Bonds on the Basis of the Charge Density, J. Phys. Chem. 99 (1995) 9747-9754. DOI: 10.1021/j100024a016. 